\title{
Relational Integration in Schools Through Seating Assignments
}

\author{
Márta Radó ${ }^{1,2,3}$ and Károly Takács ${ }^{4,3}$ \\ ${ }^{1}$ Department of Public Health, Erasmus University Medical Centre, P.O. Box 2040, 3000 CA, The Netherlands \\ ${ }^{2}$ Department of Paediatrics, Erasmus University Medical Centre - Sophia Children's Hospital, Rotterdam, The \\ Netherlands \\ ${ }^{3}$ Centre for Social Sciences, CSS-RECENS (Computational Social Science - "Lendület" Research Center for \\ Educational and Network Studies), Tóth Kálmán u. 4, 1097 Budapest, Hungary \\ ${ }^{4}$ Institute for Analytical Sociology, Department of Management and Engineering (IEI), Linköping University, \\ Norrköping SE-581 83, Sweden \\ Correspondence should be addressed tom.rado@erasmusmc.nl
}

Journal of Artificial Societies and Social Simulation 22(4) 11, 2019

Doi: 10.18564/jasss.4115 Url: http://jasss.soc.surrey.ac.uk/22/4/11.html

Received: 11-05-2019 Accepted: 13-10-2019 Published: 31-10-2019

\begin{abstract}
Traditional desegregation policies have improved but not fully solved the problems associated with the reproduction of inequalities and interracial prejudice in schools. This is partly because social networks are inherently segregated within integrated schools and the benefits of contact have not fully materialized. Therefore, new kinds of policies are needed to further improve the situation. This paper investigates the consequences and efficiency of seating arrangements on academic outcomes and prejudice using an agent-based model that reflects real-life asymmetries. We model interpersonal dynamics and study behavior in the classroom in the hypothetical case of a single teacher who defines students' seating arrangements. The model incorporates the mechanisms of peer influence on study behavior, on attitude formation, and homophilous selection in order to depict the interrelated dynamics of networks, behavior, and attitudes. We compare various seating arrangement scenarios and observe how GPA distribution and level of prejudice changes over time. Results highlight the advantages and disadvantages of seating strategies. In general, more heterogeneous deskmate pairs lead to a lower level of inequality and prejudice in the classroom, but this strategy does not favor talent management. Further, we evaluate outcomes compared to the absence of external intervention whereby students choose their own deskmates based on homophilous selection. Our model takes into account the fact that homophilous selection may be distorted due to the 'Acting White' phenomenon and pre-existing prejudice. Accounting for these factors implies slower convergence between advantaged and disadvantaged students.
\end{abstract}

Keywords: Deskmates, Academic Performance, Intervention, Social Networks, Prejudice, Acting White

\section{Introduction}

1.1 The desegregation of schools in the USA and elsewhere has been on the agenda of social scientists and policy makers since the Coleman Report (Coleman|1961, 1966). Desegregation can decrease inequality, close the racial gap in academic performance, and reduce prejudice. The resulting policies have undoubtedly improved the situation by leading to the establishment of socioeconomically mixed schools /Caldas \& Bankston III 1998; Card \& Rothstein 2007, Crain \& Mahard 1978, Schofield 1991). Inequality has decreased in school performance and attitudes have become more tolerant.

1.2 Social networks, however, even in integrated schools remain largely segregated Kao \& Joyner 2004, Moody 2001: Mouw \& Entwisle 2006, Leszczensky \& Pink 2015). Thus the problem no longer concerns the establishment of socioeconomically mixed schools, but the relational integrations therein. Therefore, to make further improvements, new methods that affect social networks within school are necessary.

1.3 To make such interventions, one would ideally need to influence friendship formation. Friendship is one of the closest relationships. Friends interact often and are mutually very influential (Lomi et al.|2011). An increasing 
amount of research has observed how friends are able to influence academic outcomes and interethnic prejudice (Brown et al.|2007, Feddes et al.|2009, Flashman|2012, Pettigrew 1997, Stark 2015). Friendship formation is largely driven by the mechanism of homophily (McPherson et al. 2001). The homophilous selection of friends, however, implies the segregation of relations. Although friends are important sources of influence, the opportunity to intervene in friendship formation is limited since teachers cannot control who will be friends with whom.

1.4 In contrast to friendship formation, teachers can exploit other mechanisms based on students' proximity to achieve certain policy objectives. In general, proximity between individuals enhances the extent of influence. Proximity may be important because of different mechanisms: exchange of help, availability of communication, and quick access to resources. Moreover, proximity may also trigger friendship formation (Newcomb 1956, 1978). Hence, interventions that utilize proximity might be helpful. This paper investigates the effectiveness of such manipulation; namely, the determination of deskmate relationships and seating in the classroom. In school settings where desks are shared and teachers determine the seating, teachers use deskmate assignment for various reasons, including disciplinary purposes, promoting desirable behavior, silencing disruptive students, managing social networks, and creating matches among diverse skills (Farmer 2000. Farmer et al. 2006 Gest \& Rodkin 2011; Hallinan \& Smith 1989). In principle, deskmate assignment could also be an effective policy measure for improving academic outcomes and reducing prejudice. Deskmates frequently interact with each other, and much of this interaction takes place in the academic context. Hence, deskmates are important sources of influence concerning academic motivation and outcomes. Previous research has confirmed that deskmates influence each other's academic performance (Keller \& Takács 2019). It has also been shown that they impact each other's level of prejudice (Radó \& Kisfalusi 2018). Moreover, deskmates often become friends, thus intervening in deskmate assignment also implies making changes in friendship networks (Back et al. 2008, Keller \& Takács 2019. Consequently, modifying seating arrangements could be a straightforward policy tool for achieving key educational objectives. Best practice strategies, however, are still not observed and there are no systematic accounts of the effect of different strategies on academic outcomes and prejudice.

1.5 It is also important to consider what happens without intervention in a classroom where students sit together at desks for two. We argue that in this case students choose friends to be deskmates, or their choice is largely based on homophily. In other words, students are likely to sit together with others who are similar to them. This endogeneity implies segregation along key dimensions of homophily: typically, gender, race, socioeconomic status, and school performance.

1.6 Homophilous selection is not the only mechanism that causes segregation in social networks. First, students with a different ethnic background might be reluctant to interact because of prejudice towards members of the other group. Second, cutting off interaction opportunities makes it perfectly possible that oppositional cultures will develop along with segregation. Agent-based models have highlighted these reinforcement dynamics Carley 1991; Mark 1998: DellaPosta et al.|2015.

1.7 Our agent-based model considers a classroom in which students are agents and the teacher is an exogenous experimenter who sets up a specific seating scenario. Students are influenced by the prejudice and academic performance of their deskmates and, to a lesser extent, by that of other members of the class. The model allowed us to examine the effect of different seating scenarios on the development of academic outcomes and prejudice. We based our model on empirical data and empirically sound theories to reflect real-world asymmetries.

\section{Background}

\section{Desegregation policies}

2.1 Scholars have proposed numerous policies aimed at achieving better educational outcomes that act through influencing contact between ethnic and social groups. These policies have mostly focused on establishing classrooms with a mixed socioeconomic or ethnic composition - for example, by introducing busing programs to reduce the inherent alignment of school segregation with residential segregation in district-based school systems. These programs have indeed enhanced the probability that students with different backgrounds will meet and, as a consequence, have decreased inequalities, including racial and ethnic differences in academic performance (Caldas \& Bankston III|1998, Card \& Rothstein 2007; Crain \& Mahard 1978) and interracial hostility Schofield 1991). It seems, however, that the benefits of these interventions have been exhausted (Moody 2001] and that the underlying problems with the reproduction of inequality and prejudice in education have not been 
fully eliminated. The problems persist because social networks within schools are still largely segregated Kao \& Joyner 2004: Moody 2001). Even if inter-ethnic friendships emerge, these relationships are less likely to persist for long and typically co-occur with less trust, perceived helpfulness, and jointly spent free time than with intra-ethnic friendships (Néray 2017; Kisfalusi 2016). Moreover, negative ties frequently emerge with peers of different ethnicity (Boda \& Néray 2015). In such circumstances, no strong integration takes place even in mixed schools that would enable equal opportunities for contact that has social capital benefits in the future.

2.2 In this paper, we analyzed a potential intervention within already integrated classrooms aimed at fostering inter-ethnic contact and further decreasing the ethnic gap in academic performance. This intervention involves manipulating the seating arrangement in a classroom. While such interventions have been associated in the past with an improvement in ethnic and racial tolerance, their analytical justification is still missing. The development of seating policies as structural interventions is relevant, as teachers can establish the seating arrangements in their classrooms. Through deskmate assignment, teachers can intervene regarding who interacts with whom, thereby establishing opportunities for targeted peer influence and friendship formation. Here, we argue that this form of intervention is not only a potential solution to the former issue but can also be an effective policy measure.

2.3 Seating arrangements have been the subject of intervention for a long time for various reasons Gremmen et al. 2017). Teachers often apply seating policies to facilitate their work. Thus, disciplinary issues and the consideration of physical attributes (e.g., wearing glasses, height, and left-handedness) are often part of teachers' motivations when they regulate seating |Keller \& Takács 2019). These strategies are often restricted to determining whether students should sit in the front or the back of the classroom, or on the right- or the left-hand side of a desk. However, some teachers apply more advanced social-network-based strategies to improve the academic performance of their students. Some studies have confirmed the relationship between seating location and academic performance (Benedict \& Hoag 2004, Buckalew et al. 1986) and translated these into practical policy recommendations (Rathvon 2008) Wannarka \& Ruhl 2008), while others report little or no support for the association (Montello 1988). Evidence-based best practice strategies have still not been identified.

\section{Deskmate relationships and academic achievement}

2.4 Intervening in seating arrangements could bring about considerable changes, as deskmates influence each other's academic achievement. In general, students' academic outcomes converge with those of their interaction partners (Flashman|2014, Fortuin et al. 2016: Gremmen et al.|2017, Rambaran et al.|2017). Even though the effect of deskmates is under-researched, there is some evidence that such peers are influential Gremmen et al. 2018. Lu \& Anderson (2014) observed the effect of the gender of deskmates on academic performance. Further, Keller \& Takács (2019) found that deskmates are able to influence each other's blind test scores even if pre-existing differences are taken into account.

2.5 There are multiple mechanisms through which deskmates could modify their partner's performance Keller \& Takács 2019. First of all, deskmates could influence each other's performance as they interact frequently during classes. Second, such students can actively help each other in preparing assignments. Third, even in the absence of communication, deskmates can directly modify their partner's academic outcomes if they copy tests. Fourth, deskmates can represent role models, thereby motivating or demotivating each other. Furthermore, deskmates' relationships often transform into friendship (Back et al. 2008, Keller \& Takács 2019), which can act to strengthen the above-mentioned mechanisms.

2.6 As deskmates influence each other, teachers can arrange desks so as to foster specific policy goals. For example, students with a less privileged background could benefit from direct help from their more privileged peers, thereby decreasing inequalities. However, advantaged students are more likely to thrive in the company of other students who are doing well Kristoffersen et al.|2015, Lavy et al. 2012). Therefore, it is important to note that achieving even a single policy goal is not free of ambiguity and that improving the academic performance of every student can hardly be achieved with any seating policy. Achieving less ambitious policy goals, such as increasing average performance or decreasing inequality is more realistic, but may mutually conflict. Simultaneously managing talent and helping students who lag behind is difficult, and represents a long-standing dilemma in educational theory and practice.

\section{Seating arrangements and prejudice}

2.7 Seating policies might also be important in terms of interracial or interethnic relations in the classroom. This is not only because desk assignments might contribute to decreasing the academic performance gap, but also 
because they could be useful for inhibiting prejudice formation. Prejudice is a set of negative attitudes towards a member of an out-group based solely on group membership status (Bar-Tal \& Teichman 2009: Brown 2011). Early adolescence and the school environment are the developmental contexts in which prejudice is crystallized Aboud 2005). Thus, reducing hostile attitudes towards minorities at this age can have life-long consequences.

2.8 In order to understand how prejudice changes at the interpersonal level in this developmental context, we need to differentiate between inter-ethnic and same-ethnic interactions. In the case of same-ethnic interactions, prejudice levels towards the out-group converge toward each other. This convergence is in line with general tendencies involving opinion and attitude dynamics in social interaction: they become more similar over time Takács et al.|2016. Peers influence each other through persuasion, but they also modify their views simply because they wish to be similar to relevant others (Dandekar et al.|2013; Deffuant et al. 2000; DeGroot 1974; Flache et al.|2017; Friedkin \& Johnsen 1990, 1997; Nowak et al. 1990; Vinokur \& Burnstein 1978).

2.9 In the case of inter-ethnic interaction, it is natural to assume the presence of a different mechanism. Such interactions expose out-group members to each other and are expected to lower prejudice against out-group members. This presumption is based on the contact hypothesis which was first introduced by Allport (1958) and has since been applied and developed (Pettigrew \& Tropp 2005, 2006). The contact hypothesis describes the conditions under which interaction efficiently works to improve inter-ethnic relations. These conditions assume cooperative and institutionally supported situations in which individuals pursue common goals and have equal status. Reviews and meta-analyses of empirical studies, however, suggest that contact might also work over a wider range of circumstances (Pettigrew \& Tropp 2005. 2006), even though the effect is larger when cross-group friends are closer to each other and spend more time together (Davies et al. 2011). Furthermore, the extended contact hypothesis argues that direct contact is not even necessary for decreasing prejudice: it is sufficient to know that an in-group member has a positive relationship with an out-group member (Dovidio et al. 2011. Wright et al. 1997; Zhou et al. 2019). The contact hypothesis is also relevant concerning cross-group deskmate relationships (Radó \& Kisfalusi 2018).

2.10 Finally, we need to take into account the fact that not only deskmates but also the entire classroom acts as a source of influence. Classmates follow and internalize norms obtained from their environment and develop their levels of prejudice accordingly. In practice, they do not adjust to the actual average opinion of the group, but to the level they perceive as the group opinion, which is often higher than the actual level, implying that individuals adjust their opinions towards a more extreme point of view. As a consequence, when inter-ethnic contact is lacking, prejudice tends to increase over time (Katz et al. 1931; Shamir \& Shamir 1997), Van Boven 2000).

\section{Deskmate selection without external intervention}

2.11 In the absence of teacher intervention, students select their desks freely. It has been demonstrated repeatedly that peer selection does not occur randomly, but homophily is a strong driver of selection (Kandel 1978; Lazarsfeld \& Merton 1954: McPherson et al. 2001). Based on homophily, we expect that individuals will sit next to others who share similar characteristics. The importance of homophily has been demonstrated empirically for friendship selection (Boda 2018, Flashman 2014, Gremmen et al. 2017; Leszczensky \& Pink 2015, De Klepper et al. 2010, Kisfalusi 2016: Munniksma et al. 2017, Rambaran et al. 2017, Smith et al. 2016: Stark 2015].

2.12 Homophilous peer selection occurs based on visible and sometimes even on latent characteristics. The most obvious traits that individuals take into account when selecting peers are gender and ethnicity. These characteristics are observable to a large extent and students heavily rely on them when selecting friends or peers (Boda 2018; Leszczensky \& Pink 2015; De Klepper et al. 2010; Kisfalusi|2016; Munniksma et al. 2017, Smith et al. 2016; Stark 2015). Less obvious, but often supported, is the fact that students also pair up with others with a similar academic background (Flashman 2014, Gremmen et al. 2017, Rambaran et al. 2017). However, such characteristics are probably more imperceptible to students, thus they do not necessarily make friendships based on this feature (De Klepper et al. 2010). Earlier research has not supported the claim that students make friendships based on the level of prejudice (Stark 2015).

2.13 Homophily, in general, is a driver of segregation. Crisscrossing actors, however, may break down cleavages. Crisscrossing actors have been defined as individuals who share at least one attribute with the out-group, thus they sometimes interact with several social groups (Evans-Pritchard|1954: Mäs et al.|2013, Simmel 1908). Due to these characteristics, these actors function as bridges across social groups.

2.14 In the classroom context, we can identify crisscrossing agents; for instance, in the dimensions of ethnicity and school performance (from now on, for the sake of simplicity, referred to as GPA). Consequently, crisscrossing agents are identified either as (1) majority students with low GPA, and (2) minority students with high GPA. To 
illustrate the role of these actors, the first column of Figure 1 shows with whom a well performing minority student would interact with under the conditions of homophilous selection. The former actors would (1) obviously interact with other minority students with high GPA, but they might also interact with (2) minority students with low GPA, as they share a similar ethnic background, and (3) majority students with high GPA, as they are similar concerning their academic performance. As a result, these actors have a higher than zero probability of interacting with individuals from a different ethnic group or with a different GPA, thus they can mediate between different groups.

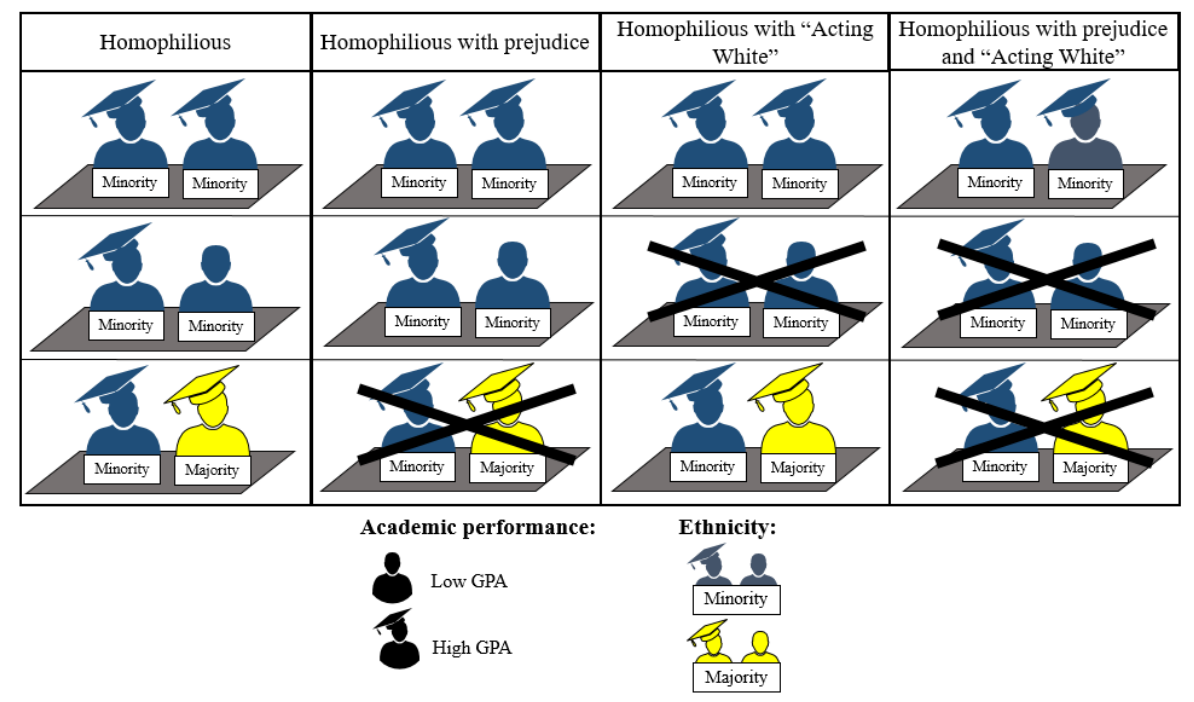

Figure 1: Feasible seating patterns for a high achieving (crisscrossing) minority student under the conditions of homophilous matching. Note: Right-hand columns take account of pre-existing prejudice and the mechanism of 'Acting White'. Left-hand side of the desk: minority student with high GPA; right-hand side of the desk: potential deskmate. Crossedout scenarios rarely happen since minority students with a good GPA are often excluded by less successful members of their ethnic group or the majority group.

2.15 Certain phenomena can strengthen segregation even in the presence of crisscrossing actors. More specifically, prejudice and 'Acting White' can significantly modify dynamics induced by homophily. We argue that these phenomena hamper crisscrossing agents in their mediating role.

2.16 First, prejudice prevents interaction between the ethnic groups regardless of their academic performance. For example, under normal circumstances a minority student might interact with a majority student if they have a similar GPA. If one of these agents, however, has an overly strong prejudice against the other group, then this relationship cannot be realized. The second column of Figure 1 illustrates this case.

2.17 Second, 'Acting White' can prevent interaction between high performing and low performing members of the disadvantaged minority. The concept of 'Acting White' refers to the situation in which the minority group excludes its own high achieving members as these members are considered to betray minority culture as they live up to the expectations of the majority culture (Ainsworth-Darnell \& Downey 1998; Cook \& Ludwig| 1997; Fordham \& Ogbu 1986 Fryer Jr. \& Torelli 2010; Kertesi \& Kézdi 2005). This phenomenon creates obstacles to higher performing minority students in terms of their interaction with and sitting next to lower achieving same-ethnic peers. This case is shown in the third column of Figure 1

2.18 Finally, if both prejudice and 'Acting White' exist in the classroom, then a crisscrossing actor will not be able to bridge any of the dimensions. For instance, a high achieving minority student would only be likely to interact with other high achieving minority individuals. This case is displayed in the last column of Figure 1

\section{Research questions}

2.19 We studied the effects of the following seating arrangements on policy goals: (1) homophilous (occurring in the absence of the teacher's intervention), (2) heterophilous, (3) desegregation, (4) sorted, (5) best with worst, (6) best with median, and (7) random.. We estimated how results change when two context-specific phenomena, 'Acting White' and pre-existing prejudice, operate. We estimated the effect of seating arrangements on four different policy objectives and analyze the development of (1) inequalities, (2) talent management, (3) the ethnic gap in academic performance, and (4) the average level of prejudice against minorities. 


\section{The Model}

3.1 Our model represents a classroom with one teacher and a defined number of students. The teacher is an experimenter, whose manipulation of seating arrangements is the main independent variable in our analysis. The teacher intervenes by organizing the classroom in a way that each student receives one deskmate. Students as agents make adjustments to their academic achievement and prejudice levels in relation to the social influence of their deskmates and the overall classroom. The outcome variables of interest are achievement, inequalities, and prejudice, as described in the section entitled 'Outcome variables'. Figure 2 summarizes the model.

3.2 At the stage of initialization, classroom characteristics are set up based on empirical data. They have an invariable binary characteristic of ethnicity and two variable characteristics; namely, GPA, and level of prejudice against the out-group. The initial model set-up is detailed in the section entitled 'Parameter set-up'.

3.3 Furthermore, the teacher chooses between seven types of seating (as detailed in Section 'Seating arrangements'). Consequently, seven versions of the model may be constructed, each representing one seating arrangement. In each time step, the classroom is re-arranged following the given seating principle. For instance, in the case of homophilous selection students could be paired with different deskmates than before as a result of changing levels of similarity.

3.4 Due to the model dynamics, three changes can occur in each step. First, every agent receives a deskmate following the logic of the initially predefined seating arrangement. In practice, this means that agent pairs are created. Second, variable individual characteristics, such as GPA and prejudice are influenced by deskmates (see Section 'Deskmate influence'). Third, agent characteristics are also affected by the classroom environment (See Section 'Classroom effects on agent characteristics').

3.5 While it is difficult to unambiguously translate the frequency of simulation steps to real time, a natural way to link simulations to empirical observations is to consider one step in the simulation as one semester of real time. Just as seating re-allocation occurs, tests of academic performance are administered in surveys from time to time. In the empirical data we refer to, measurements took place once every semester. In practice, however, seating arrangements could be the subject of intervention more or less frequently, which would modify the relative pace of effects.

3.6 For each seating scenario, we ran the models with a default set parameter configuration 1000 times. We reported means, standard deviations, and the spread of the outcome variables in the first 15 steps $^{1}$. Subsequently, we analyzed the sensitivity of our findings in some important dimensions. More specifically, we checked how seating scenarios perform with regard to academic achievement, inequalities and prejudice when we modified (1) the number of minority students, (2) weights relating to how deskmates influence each other's GPA, and (3) the initial GPA of minority students.

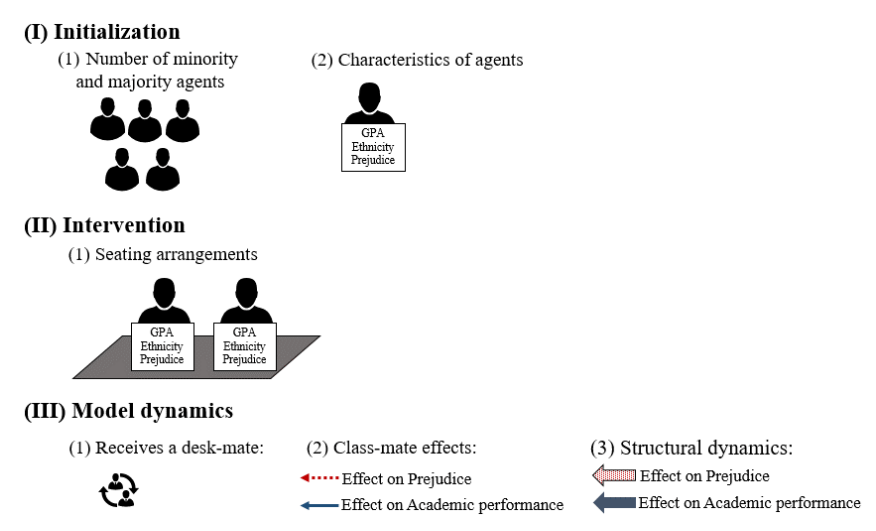

Figure 2: Model overview I. 


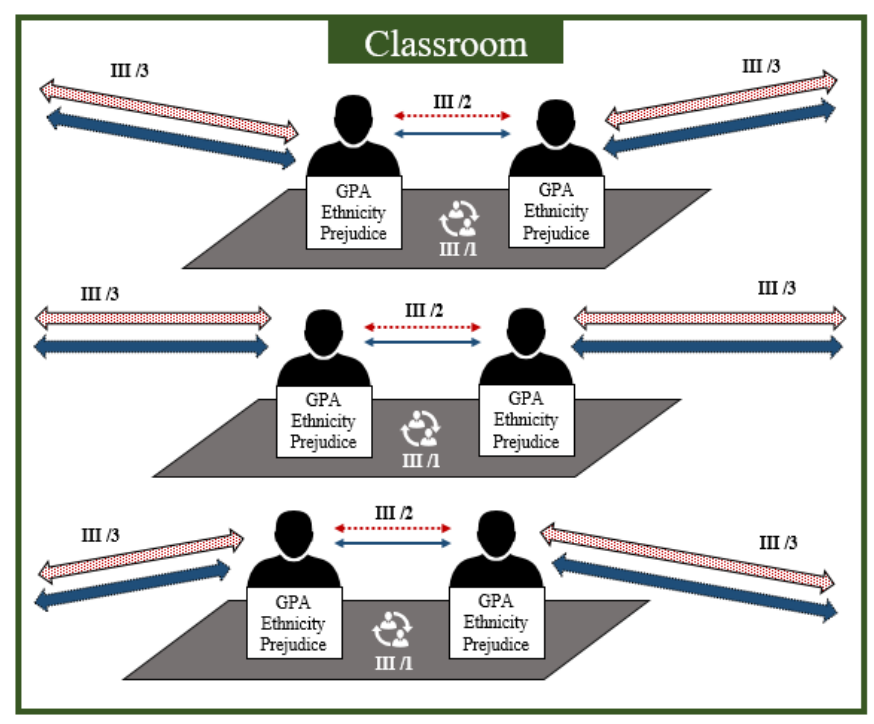

Figure 3: Model overview II.

\section{Parameter set-up}

3.7 We initialized agent characteristics following inspiration from an empirical dataset from Hungary in which students were typically seated at two-person desks. The related dataset "Wired into Each Other" was collected in the spring of 2016 by the MTA TK "Lendület" Research Center for Educational and Network Studies (RECENS). The sample consisted of 832 seventh-grade students from 47 classes with a mixed ethnic (Hungarian and Roma) composition. Roughly $45 \%$ of the sample self-reported to being Roma, and $55 \%$ Hungarian. This proportion was used in our simulation for every class. To obtain even numbers for each group, a classroom size of 40 was chosen.

3.8 GPA was measured in the empirical sample as the average grade for five main subjects. Subjects were graded on a scale from 1 (worst) to 5 (best). The mean GPA for Roma students was 2.6, and 3.6 for non-Roma students. In the empirical data, excellent grades (5.0) occurred relatively frequently, but GPA scores were otherwise normally distributed. For the sake of simplicity, in the simulations we applied a normal distribution to the grades in which the means and standard deviations were empirically informed. As a point of reference, the mean nonRoma average GPA was set to 100. The standard deviation of non-Roma GPA was 33. Proportionally to the differences in the empirical data, the average GPA of Roma students was set to 72 in the simulations, with a standard deviation of 11.

3.9 Prejudice levels were defined proportional to empirical findings. In the empirical survey, respondents were asked whether they would like to (1) be a friend, (2) go to the same class, (3) be a neighbor, and (4) live in the same settlement with someone with a Roma/non-Roma ethnicity. On average, non-Roma rejected Roma twice as often ( 3 items) as Roma rejected non-Roma (1.6 items). The empirical data also showed a consistent level of prejudice against Roma students among the Roma themselves, similar to the level of prejudice of Roma students against non-Roma students. In general, prejudice against Roma could closely be approximated by a uniform distribution. For the sake of simplicity, we also applied a uniform distribution for prejudice values against non-Roma students. Starting values for prejudice in the simulations were chosen to reflect empirical findings, but were scaled up to better allow for subtle differences and shifts. We scattered the prejudice level of Non-Roma students against Roma in an interval between 0-66. Since Roma students were approximately half as prejudiced against Non-Roma in our empirical dataset, the parameter of prejudice of the Roma against non-Roma students took a value prejudice of between 0-33, following a uniform distribution. For the sake of simplicity, this model did not incorporate the in-group prejudice level.

\section{Seating arrangements}

3.10 We investigated seven different seating arrangements. The teacher as the experimenter chooses a seating arrangement at the stage of initialization, and this principle guides the seating arrangement for the entire simulation. Based on the selected principle, at each step every student receives another student as a deskmate. 
Other issues regarding seating location such as the allocation of front and back seats in the classroom are not analyzed. This way, the location of seats is considered not to have any effect on the outcome variables and does not cause any heterogeneity. Further, we assumed that the composition of the classroom does not change during the simulation process, thus any change observed is due to the seating arrangements. Hence, we focus on the consequences of deskmate effects in the classroom.

3.11 The teacher can initially choose between the following seating arrangements: (1) homophilous, (2) heterophilous, (3) desegregation, (4) sorted, (5) best with worse, (6) best with median, and (7) random. The different seating scenarios apply a different system of matching that allocates individuals to pairs. Figure 4 illustrates the different seating scenarios in which the color of the agent indicates their ethnicity, their order specifies their GPA level, and the green lines show potential matching according to the given seating policy.

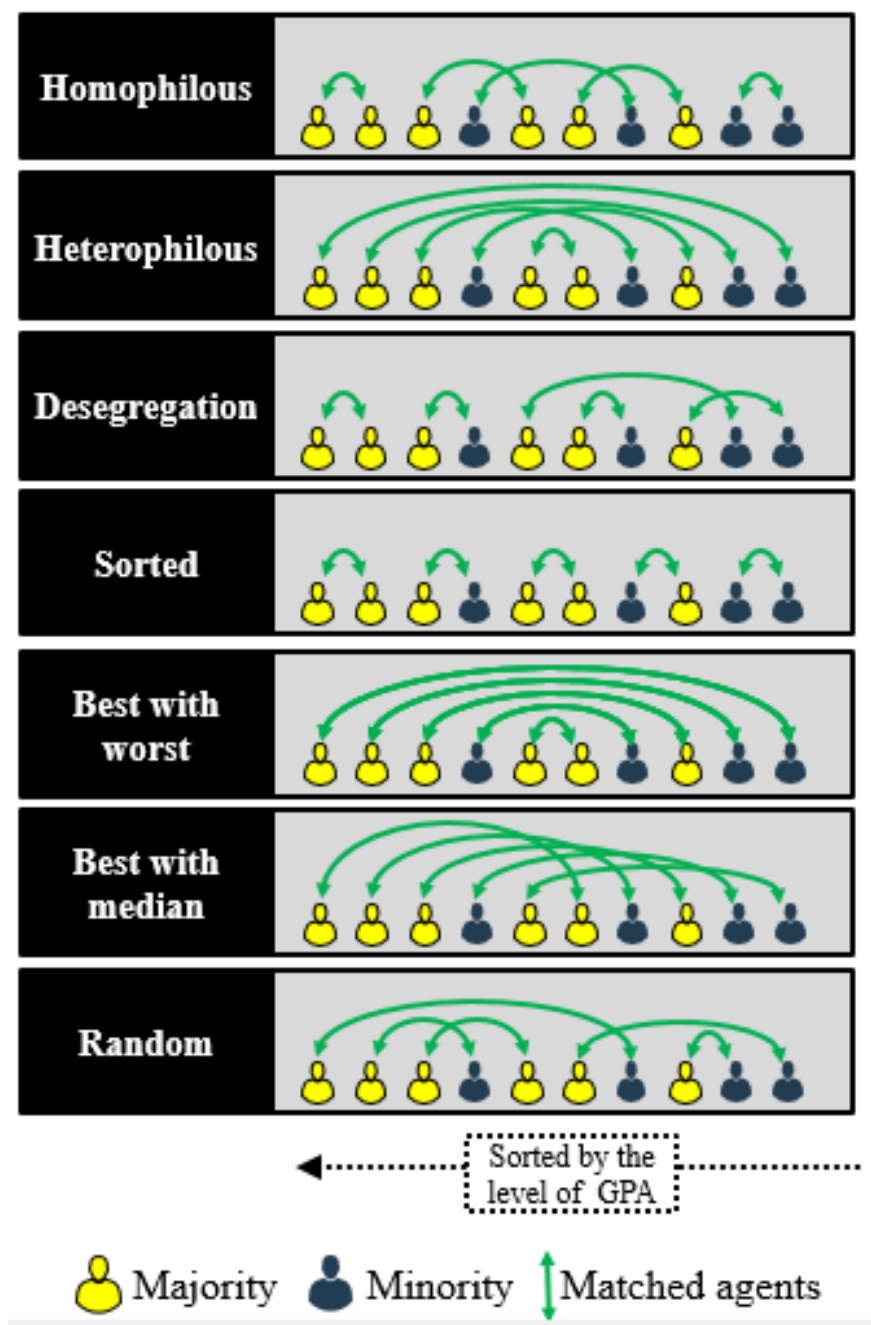

Figure 4: Applied seating arrangements.

3.12 First of all, homophilous seating imitates how students would choose their own deskmates in the absence of external intervention. Under this scenario, students would sit next to those who are similar to them along the dimensions of academic achievement and ethnicity. To formalize this, a difference score for each $i$ agent and $j$ potential deskmate was calculated based on GPA score and ethnicity:

$$
\text { Difference }_{i}=\left|G P A_{i}-G A_{j}\right|+\mid \text { Ethnicity }_{i}-\text { Ethnicity }_{j} \mid \times 10+\gamma_{i j} \text {, }
$$

where $\gamma_{i j}$ signifies uniformly distributed random noise in the interval 0 to $100-$ this was included as the two agents can differ from each other in factors other than their ethnicity and GPA (e.g. gender, or hobbies).

3.13 After the calculation of the difference score for each potential link, desks were formed according to the following algorithm. First, in the case of homophilous seating the pair with the smallest difference score was selected, and then selection continued in increasing order. It is important to note that each agent could be selected only once. 
Thus, if an agent had already been selected, all other potential links to this agent were removed from further consideration. This search mechanism is referred to as a local search mechanism that is an iterative process which is optimized in each iteration (i.e. student ordering based on the difference score and pairing of the former with the available classmate with the smallest difference). There are other search algorithms that are designed to find the best possible solution globally (i.e. to minimize total classroom deskmate difference), not simply the local optima (Selman \& Gomes 2006). However, these search mechanisms are way more complex and unlikely to give significantly different results than ours. Furthermore, a local search mirrors a real-life pair selection process in which close friends pair up first, and less well connected agents choose each other subsequently.

3.14 Besides simple homophilous matching, we extended the observation of these seating arrangement scenarios to account for pre-existing prejudice and the phenomenon of 'Acting White'. First, two agents of different ethnicity could sit next to each other based on their difference score, but this relationship was not permitted if one of them was too strongly prejudiced against the other's ethnic group. More formally, the difference score of a potential link (see the calculation of this score in Equation 11) was increased by fifty if one member of the inter-ethnic peer had a prejudice level against the out-group greater than 10. Second, when the matching algorithm took account of the phenomenon 'Acting White', the probability of interaction between minority students with different academic outcomes was decreased. To account for this phenomenon we again added fifty to the difference score of every potential link between Roma students who had ten or more points difference in their GPA. After creating the new difference scores for every potential link, agents were matched in the same way as was defined for the homophilous seating scenario using these new scores.

3.15 Second, teachers could decide to enforce a seating order in exactly the reverse way to the homophilous seating approach. We refer to this scenario as a heterophilous seating arrangement. Under this scenario, potential links are selected in a way that first the pair with the largest difference score is matched, and then matching is continued in decreasing order of the difference scores.

3.16 Third, teachers could merely follow the logic of desegregation but in a way as to promote academically similar pairs at the same time. This scenario is similar to the homophilous scenario, but instead of fostering sameethnic pairs we foster mixed-ethnic pairs. To set up this scenario we calculated a desegregation score for every potential link:

$$
\text { Desegregation }_{i j}=\left|G P A_{i}-G P A_{j}\right|+\mid \text { Ethnicity }_{i}-\text { Ethnicity }_{j} \mid \times(-50)+\gamma_{i j} \text {, }
$$

3.17 Under this scenario, agents are paired in the same way as in the case of homophilous seating, but instead of the difference score we minimize this desegregation score. Note that the two scores differ only in terms of penalizing or rewarding ethnically different pairs.

3.18 Other seating arrangements involved the selection of deskmates solely based on their GPA rank. Based on this logic, the fourth seating scenario involved sorting the highest ranked agent with the second best one, the third to the fourth, and so on until the worst performing two students were paired. In contrast, the fifth seating scenario, best with worse, matched the student with the highest GPA to the one with the lowest, the second highest to the second lowest, and so on until the two median agents were paired as deskmates. In the bestwith-median seating arrangement (scenario six) the rank difference was made constant between deskmates. This seating scenario locates the best student next to the student with the median score, the second best with the agent who is ranked one place below the median student, the third best with the student ranked two below the median student, and so on (Figure 3). Finally, deskmate pairs could be created randomly.

\section{Deskmate influence}

3.19 Peers influence each other's variable characteristics, such as level of prejudice and academic achievement (GPA). We formalize social influence similarly to as is done in opinion dynamics models. Namely, the new value of an individual characteristics is the weighted mean of the individual's own position (larger weight) and that of the peer's position. Further, peer influence may be asymmetrical (Lomi et al. 2011): better performing students help weaker students more than poor performers hinder good performers. If $i$ agent had a higher GPA than his or her $k$ deskmate, then the GPA score of $i$ changed between $t$ and $t+1$ time in the following way:

$$
G P A_{i}^{t+1}=\left(9 \times G P A_{i}^{t}+G P A_{k}^{t}\right) / 10 \quad \text { if } G P A_{i}^{t}>G P A_{k}^{t}
$$

3.20 In contrast, if $i$ agent had a lower GPA than his or her $k$ deskmate, then $i$ agent's new GPA score was defined as:

$$
G P A_{i}^{t+1}=\left(4 \times G P A_{i}^{t}+G P A_{k}^{t}\right) / 5 \quad \text { if } G P A_{i}^{t}<G P A_{k}^{t}
$$


3.21 These asymmetrical tendencies that weight the position of better achievers relatively higher result in an overall trend to improvement in the class.

3.22 Further, deskmates influence the prejudice level of each other. Inter-ethnic and same-ethnic deskmates influence each other in a different way. If $k$ deskmate belongs to the same ethnic group as $i$, then their out-group prejudice levels converge to each other, which observation is in line with simple models and experiments of opinion dynamics and social influence (e.g., Friedkin \& Johnsen 1990, 1997; Takács et al.|2016. Thus the new prejudice level of $i$ is given as:

$$
P J_{i}^{t+1}=\left(4 \times P J_{i}^{t}+P J_{k}^{t}\right) / 5
$$

where $P J$ refers to the level of out-group prejudice.

3.23 The situation is different for deskmates of different ethnicity. Based on the contact hypothesis, we assumed that their interaction would decrease their level of prejudice. Consequently, if $i$ agent belonged to a different ethnic group to $k$ deskmate, then $i$ agent's level of prejudice against the out-group would decrease (see Equation 6 . We assumed that intergroup contact would have a similar influence on prejudice among members of majority and minority groups (Davies et al. 2011).

$$
P J_{i}^{t+1}=P J_{i}^{t} \times \frac{4}{5}
$$

\section{Classroom effects on agent characteristics}

3.24 Students are members of a well-bounded class, hence not only deskmates but to a lesser extent other members of a class might affect the variable characteristics of agents. Consequently, there is a peer effect for the classroom level, but its size is marginal compared to the desk-mate effect. In this model we assume that the classroom effect remains constant over time in order to disentangle the seating arrangement effect from other social mechanisms that operate in the classroom.

3.25 We incorporated classroom influence into the model the following way. First, we assumed that the general academic climate in the class would slightly increase or decrease each individual result. We considered the classroom average GPA score and a small shift towards the mean value. Specifically:

$$
G P A_{i}^{t+1}=\left(99 \times G P A_{i}^{t}+G P A_{\text {class }}^{t}\right) / 100
$$

3.26 Besides academic outcomes, the level of prejudice against minority students is also influenced by non-Roma members of the class. The $A P M i_{e c}$ actual level of prejudice against the minority in the $c$ classroom is the average of $e$ majority members' level of prejudice:

$$
\mathrm{APMi}_{e c}=\frac{\sum_{e=1}^{e} P J_{e}}{e}
$$

3.27 Moreover, we assumed that individuals do not simply adjust to the actual average level of prejudice of their surroundings. Informed by pluralistic ignorance theory (Fields \& Schuman 1976, Katz et al. 1931, Shamir \& Shamir 1997; Van Boven 2000, we assumed that perceptions are biased such that people tend to overestimate the level of prejudice in their environment. Thus, in the case of no inter-ethnic interaction, pluralistic ignorance theory suggests a gradually increasing level of prejudice in a class. We formalized this bias by differentiating between the $A P M i_{e c}$ actual and $P P J_{e c}^{t}$ perceived levels of prejudice in the $c$ class and assumed a linear shift:

$$
P P J_{e c}^{t}=A P M i_{e c}^{t}+3=\frac{\sum_{e=1}^{e} P J_{e}^{t}}{e}+3
$$

3.28 This perceived prejudice level in the classroom modifies the actual prejudice level of each majority member of the class, thus:

$$
P J_{e i}^{t+1}=\left(99 \times P J_{e i}^{t}+P P J_{e c}^{t}\right) / 100
$$

\section{Outcome variables}

3.29 We concentrated on two major policy outcomes: academic outcomes and prejudice. There can be different policy objectives concerning academic outcomes. A policy could target the general level of inequalities, talent management, and ethnic inequalities. First, we address how deskmate assignment influences the development 
of inequalities. To measure this, we compared how the average GPA of the bottom 10\% students relates to the average GPA of the top $10 \%$ of students. This measurement is often used for understanding inequalities - for example, in OECD reports (OECD 2018). This measurement is referred to as 90/10 in this paper. Specifically, students are ranked based on their GPA and the measure is defined as the sum of the GPA of the top 10\% of ranked students divided by the sum of the GPA of the bottom $10 \%$ of ranked students. Second, a policy could aim at assisting talented students. We therefore use an outcome measure that describes the average GPA of the top $25 \%$ students. Third, policies could address ethnic differences. The ethnic gap in academic performance could be depicted by the ratio of the average GPA score of the minority to that of the majority group. This ratio is referred to as an ethnic gap measure. Fourth, a policy could be concerned about the average level of prejudice against Roma among non-Roma. In our simulations, the trajectory of class-level prejudice against minorities is traced.

\section{Sensitivity analyses}

3.30 We tested the sensitivity of our results derived from the baseline model (i.e. the model with the above-described parameters) to (1) the GPA of minority agents, (2) the number of minority agents, and (3) the extent to which deskmates influence each other's GPA. First, we tested how sensitive the results are to defining the initial minority GPA as 95 instead of 72 . Second, we tested how results change when the number of minority agents is 4 , whereas the number used in the baseline model is 18 . Finally, we checked how the results change when better achieving students influence their deskmates to a lesser extent (a lower weight) than in the baseline. We applied Equation 3 to both lower and higher achieving deskmates instead of using Equation 4 for lower achieving deskmates. In this paper, we report a summary of our sensitivity analysis, while detailed results are available in the Supplementary Material.

\section{Results}

\section{Inequalities}

4.1 We start by reporting results about how inequalities develop under different seating scenarios. More specifically, we observe the development of the ratio of the average GPA of the $10 \%$ best performing- to the $10 \%$ worst performing students. Intuitively, the expectation was that creating academically heterogeneous pairs should dampen inequality.

4.2 Figure 5 shows that our intuition was supported. Inequality decreases the most when using "best with worst" seating, or a heterophilous arrangement. Although the latter scenario not only differentiates based on academic achievement (as the previous one does) but also takes into account ethnicity, these two seating policies produce similar results. In contrast, inequality is the greatest when agents with different levels of academic performance are separated. This is clearly the case with sorted seating arrangements, which create the highest number of academically homogeneous pairs. Our results also show that homophilous seating can considerably contribute to increasing inequality. This implies that a laissez-faire seating approach would foster the proliferation of inequality. The latter seating scenario is even worse in terms of promoting inequality than a random seating assignment. Finally, desegregation cannot decrease inequalities to such a high level as a heterophilous seating approach. Thus merely creating mixed ethnic pairs without making these pairs academically different is not enough to reduce inequalities. 

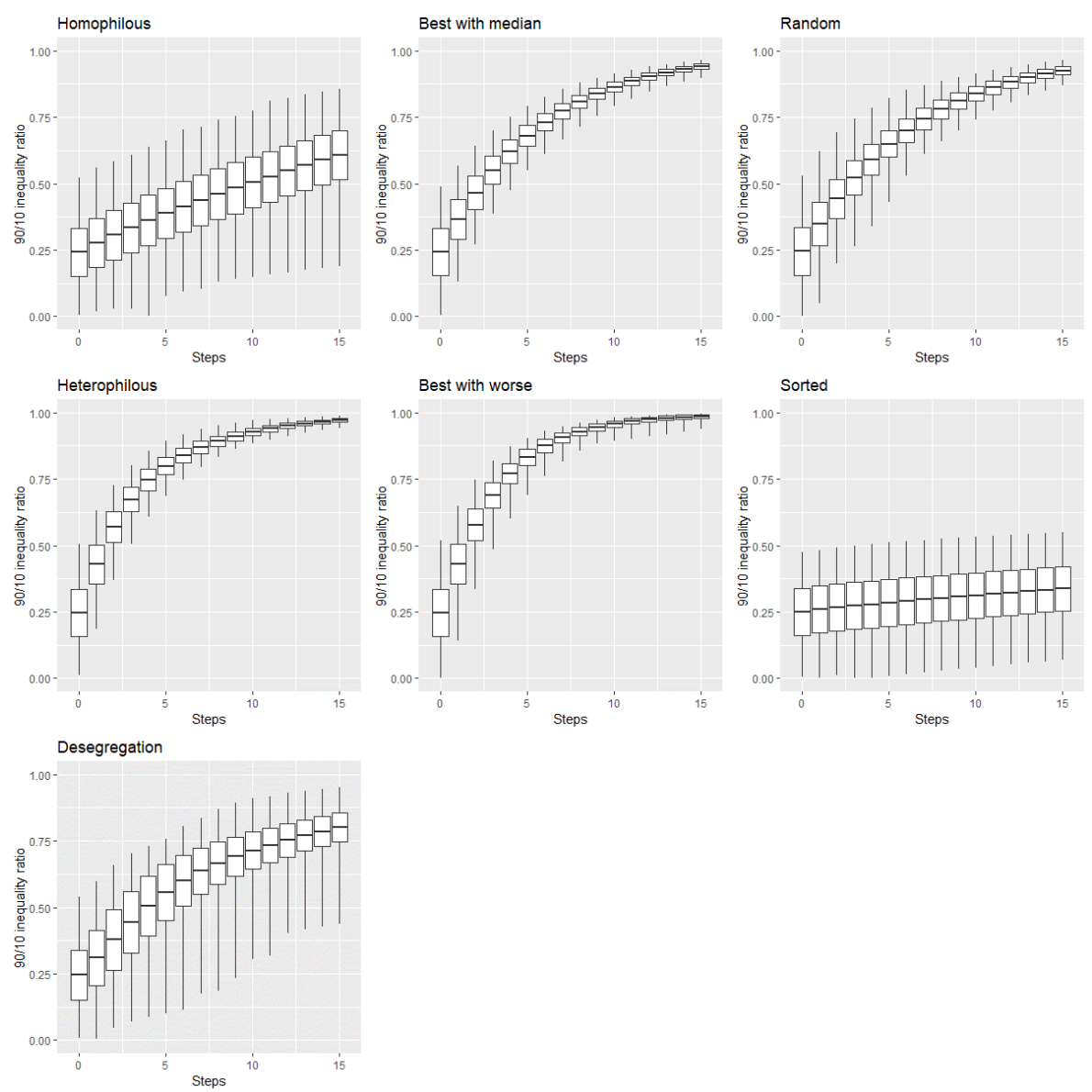

Figure 5: Progression of inequality according to different seating arrangements.

4.3 As shown in Figure 5 , homophilous seating does not favor a reduction in inequality, and this scenario is even worse when we take into account pre-existing prejudice and the 'Acting White' phenomenon. Interestingly, Figure 6(left panel) shows that prejudice alone does not worsen inequalities. In this case low achieving Roma students cannot receive help from non-Roma students. However, they might interact more with successful Roma peers who cannot interact with similarly successful non-Roma students. Cutting off contact with non-Roma peers is less of a loss for minority students, since based on homophily they would in any case interact with less successful non-Roma who cannot academically motivate others. In contrast, the existence of the 'Acting White' phenomenon (see middle panel in Figure 6) instantaneously increases inequalities. In this case, less competent Roma students lose help from peers who would otherwise push them to study better. Finally, the situation is the worst when both 'Acting White' and pre-existing prejudice are entered into the simulations (see the right-hand panel in Figure 6. In this case, Roma students with high GPA are entirely marginalized because they cannot interact with either less competent Roma or academically successful non-Roma students. 


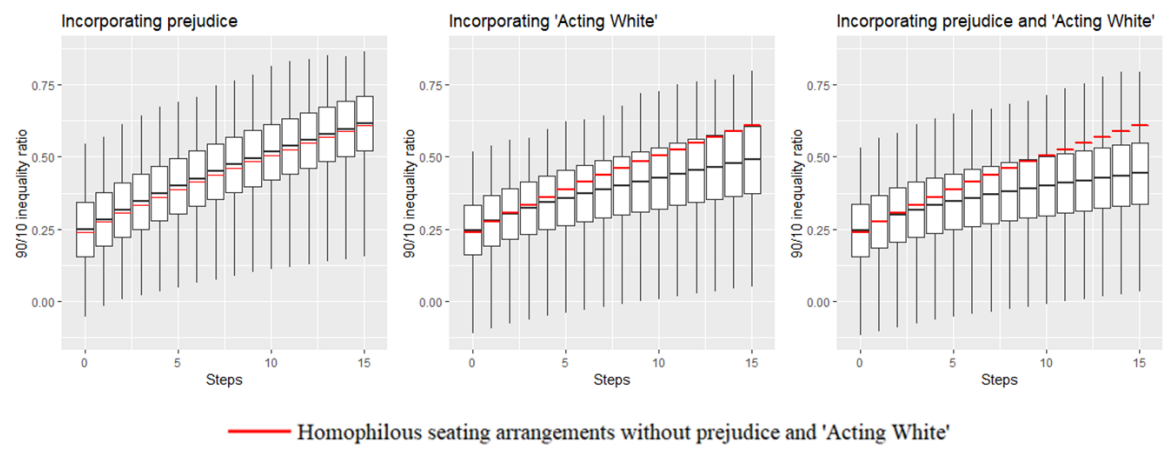

Figure 6: How prejudice and the 'Acting White' effect modify the effect of homophilous seating assignments on inequality.

\section{Talent management}

4.4 Despite the above-mentioned advantage of creating academically heterogeneous pairs, the heterophilous seating arrangement has clear disadvantages for talent management. Figure 7 shows how the average GPA score of the top 25\% progresses under different seating arrangements. Our simulation reveals that the policy objective of talent management clearly conflicts with the goal of lessening inequality. Talent management thrives when talented agents can interact frequently with other talented peers. Thus, a sorted arrangement is most beneficial in terms of talent management. Accordingly, a homophilous setting also benefits this purpose. In other words, giving students the freedom to choose their own deskmates is likely to foster the academic development of the most talented students. However, 'best-with-worse', 'best-with-median', and heterophilous seating policies would create obstacles to achieving this policy objective.
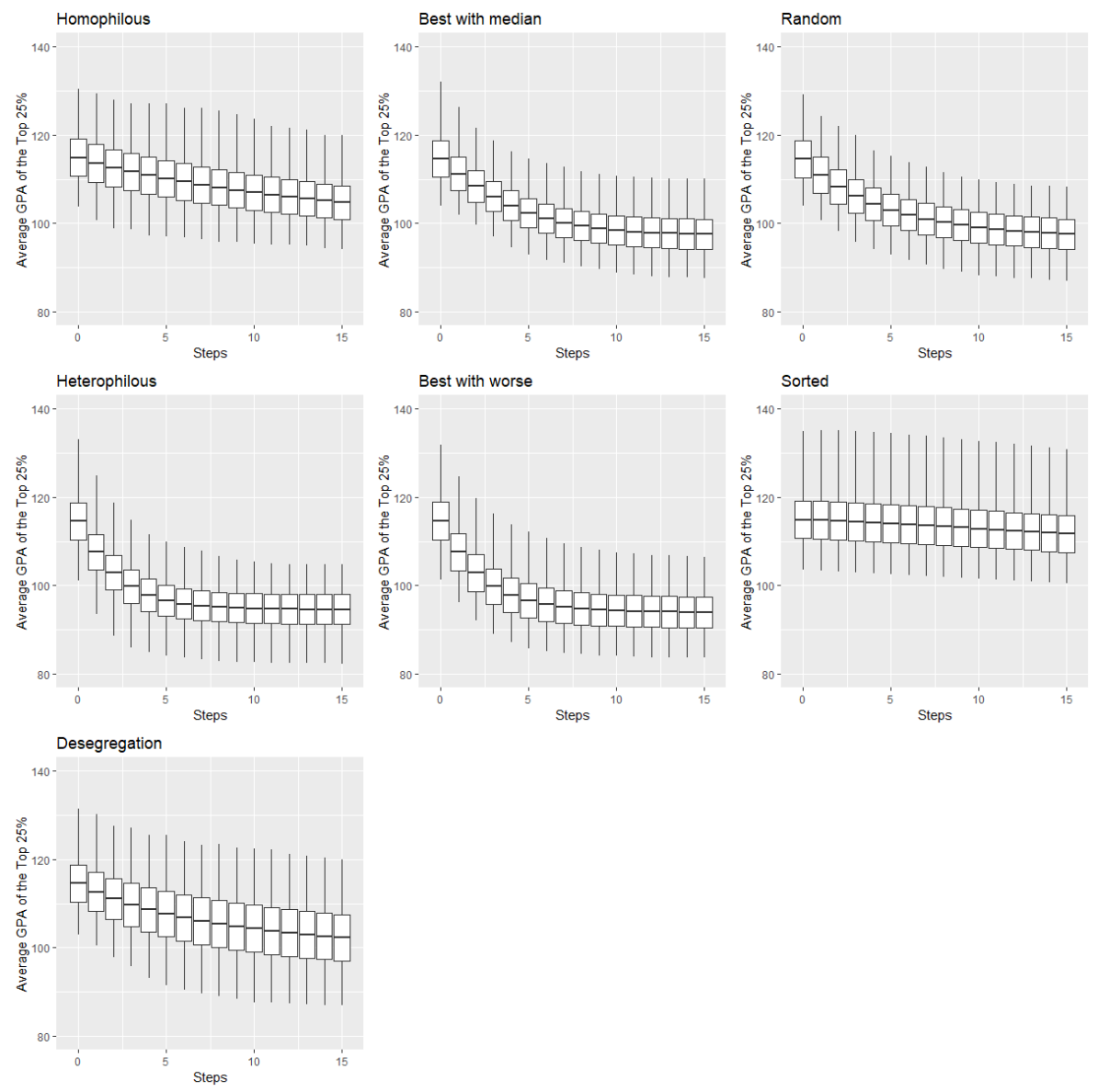

Figure 7: Progression of average GPA of top $25 \%$ of students according to different seating arrangements. 
4.5 Simulations show that the presence of prejudice and 'Acting White' only slightly modify the effect of a homophilous seating arrangement on talent management. Prejudice without 'Acting White' to some extent worsens talent management, since in this case high achieving non-Roma agents exclude their similarly talented Roma peers (see the left-hand panel in Figure 8). However, prejudice and 'Acting White' together have a vanishingly small positive effect on talent management (see the right-hand panel in Figure 8). The reason for this is that excluded but talented Roma students can at least interact with each other, which favors the policy goal of talent management.

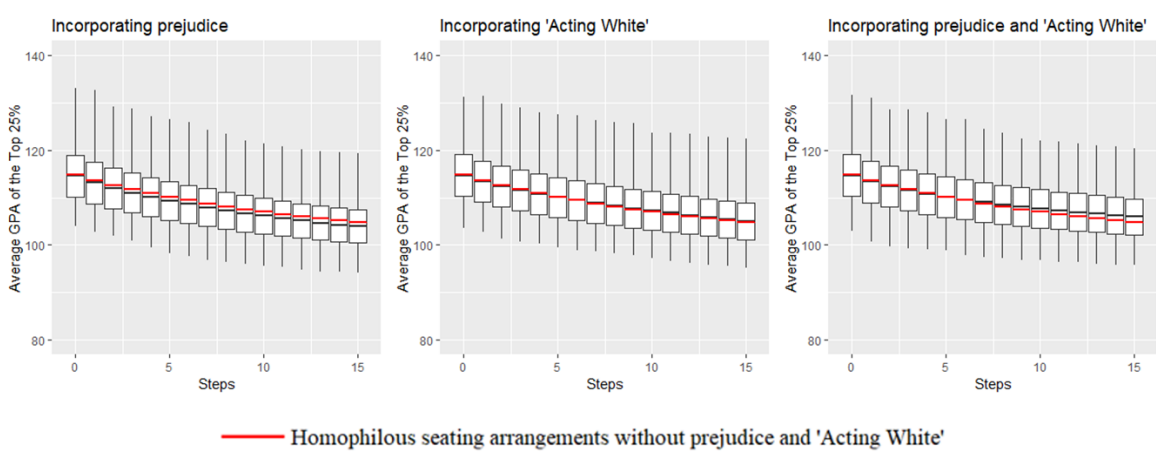

Figure 8: How prejudice and 'Acting White' modify the effect of a homophilous seating arrangement on talent management.

\section{Inequalities between ethnic groups}

4.6 Another important policy goal is closing the ethnic gap in academic performance between minority and majority students. Figure 9 shows how the ethnic gap measure improves under all seating scenarios. The results confirm the intuition that this policy goal is best assisted with a similar seating policy to that which decreases general inequality. Heterophilous seating can decrease ethnic inequalities the best, along with heterophilous seating and best-with-worse seating. But best-with-median, desegregation, and random seating policies also work relatively well for this purpose. 

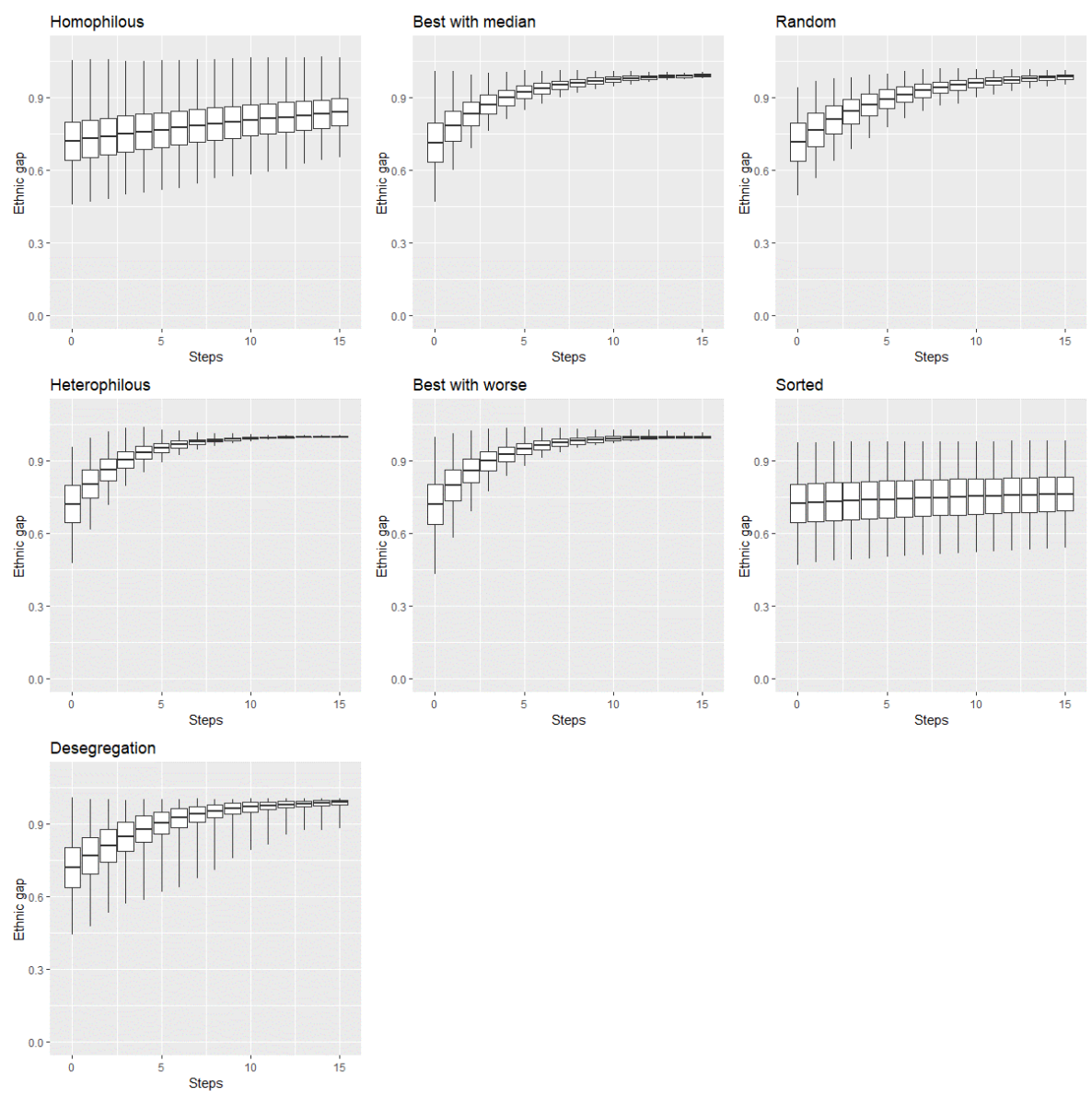

Figure 9: Progression of ethnic gap according to different seating arrangements.

4.7 Homophilous seating does not work well to decrease inequalities between ethnic groups. This seating scenario produces even worse results once we take into account the presence of prejudice and 'Acting White' (see Figure 10). Both phenomena work against efforts to help minorities catch up academically. Prejudice isolates minorities, whereas 'Acting White' segregates talented minority students from their own ethnic group. When these two phenomena operate simultaneously, minorities have difficulties escaping their disadvantaged positions.
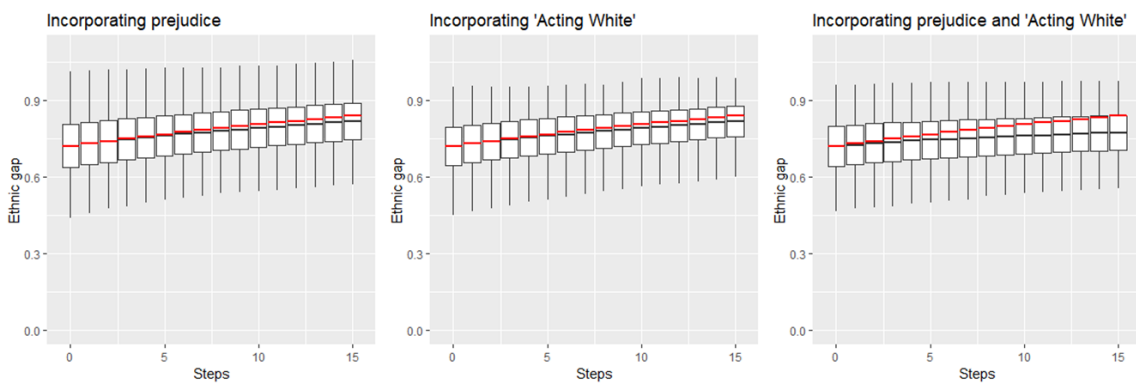

— Homophilous seating arrangements without prejudice and 'Acting White'

Figure 10: How prejudice and 'Acting White' modify the effect of a homophilous seating on the ethnic gap.

\section{Class-level prejudice against minorities}

4.8 It is a fundamental policy goal to decrease prejudice against minorities. Thus it is also important to understand how this measure changes under different seating scenarios (see Figure 11). Our simulations show that a 
desegregation-based seating approach works best for this purpose, whereas homophilous and sorted seating is the worst. Other scenarios do not modify this measure significantly.

4.9 This result can be attributed to the different extent of interactions between minority and majority students under different seating scenarios. Desegregation and heterophilous arrangements result in the highest likelihood of mixed ethnicity pairs. More specifically, on average $87 \%$ and $86 \%$ of deskmate dyads are ethnically mixed under these seating strategies, respectively. In comparison, this proportion is only $17 \%$ in the case of homophilous seating.
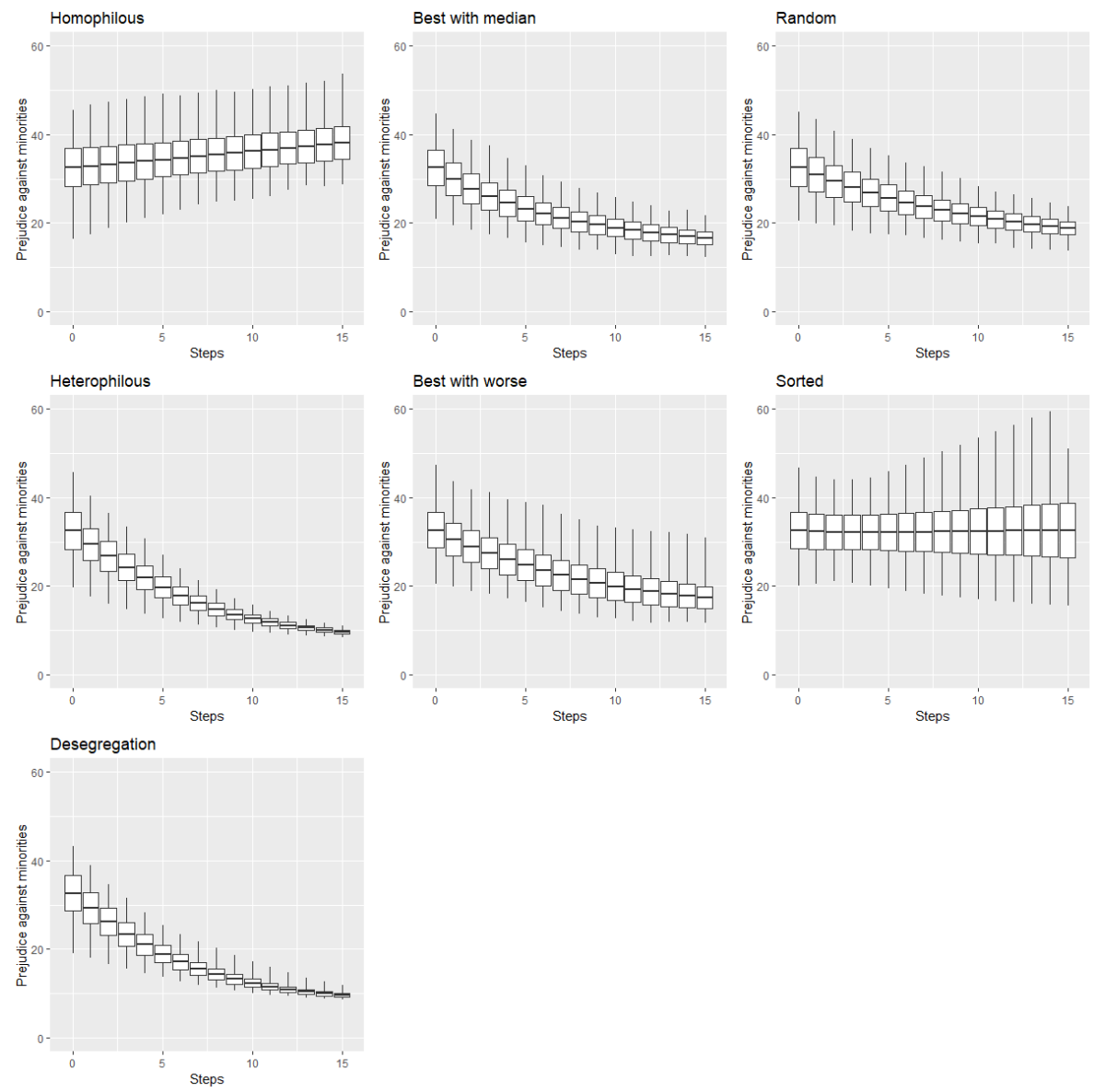

Figure 11: The development of class-level prejudice against minorities according to different seating arrangements.

4.10 Again, homophilous deskmate selection leads to different results when prejudice and 'Acting White' are taken into account (see Figure 12. Unsurprisingly, pre-existing prejudice blocks interactions between ethnic groups, which results in an even higher level of prejudice (see left panel in Figure 12). In contrast, 'Acting White' can even mitigate the level of prejudice in the classroom somewhat (see middle panel in Figure 12. This phenomenon blocks interaction within the minority group, which leads to an increase in inter-group contact. This is only achieved, however, when majority students do not refuse to interact with academically successful minority students. Thus, if both prejudice 'and Acting White' are present in the classroom, then prejudice sharply increases under conditions of homophilous selection (see right panel in Figure 12 . 


\begin{tabular}{|c|c|c|c|c|c|c|c|c|c|c|c|c|}
\hline \multirow{3}{*}{$\begin{array}{l}\text { Policy Goals } \\
\text { Seating Manipulation }\end{array}$} & \multicolumn{3}{|c|}{ Reducing inequalities } & \multicolumn{3}{|c|}{ Improving talent management } & \multicolumn{3}{|c|}{ Reducing ethnic gap } & \multicolumn{3}{|c|}{ Reducing prejudices } \\
\hline & (1) & (2) & (3) & (1) & (2) & (3) & (1) & (2) & (3) & (1) & (2) & (3) \\
\hline & & - & & + & + & & & 0 & & 0 & $\ldots$ & 0 \\
\hline Desegregation & - & - & - & + & + & - & - & - & - & 0 & -. & 0 \\
\hline Best with median & - & - & .. & + & + & .. & - & 0 & .. & 0 & -. & 0 \\
\hline Best with worse & - & - & -- & + & + & -. & - & 0 & -. & - & -. & 0 \\
\hline Sorted & 0 & 0 & 0 & 0 & 0 & 0 & 0 & 0 & 0 & + & - & 0 \\
\hline Random & - & - & .. & + & + & .. & - & 0 & .. & 0 & -. & 0 \\
\hline $\begin{array}{l}\text { Homophilous disregarding prejudice and } \\
\text { 'Acting White' }\end{array}$ & 0 & 0 & - & 0 & 0 & - & 0 & + & - & 0 & - & 0 \\
\hline Homophilous incorporating prejudice & - & - & - & 0 & + & - & 0 & 0 & - & 0 & 0 & 0 \\
\hline Homophilous incorporating 'Acting White' & 0 & - & - & 0 & + & - & 0 & + & - & 0 & 0 & 0 \\
\hline $\begin{array}{l}\text { Homophilous incorporating and 'Acting } \\
\text { White' }\end{array}$ & - & - & - & 0 & 0 & - & 0 & 0 & 0 & 0 & 0 & 0 \\
\hline
\end{tabular}

Table 1: Sensitivity to manipulation of (1) higher average GPA of minority students, (2) smaller proportion of minority students, and (3) smaller influence that better-achieving deskmates have on their lower achieving deskmates: How do these manipulations modify the effect of seating scenarios on certain policy goals compared to the baseline model? (+: policy goal is achieved faster; 0: neutral; -: policy goal is achieved more slowly). Note: Detailed simulation results are available in the Supplementary Appendix

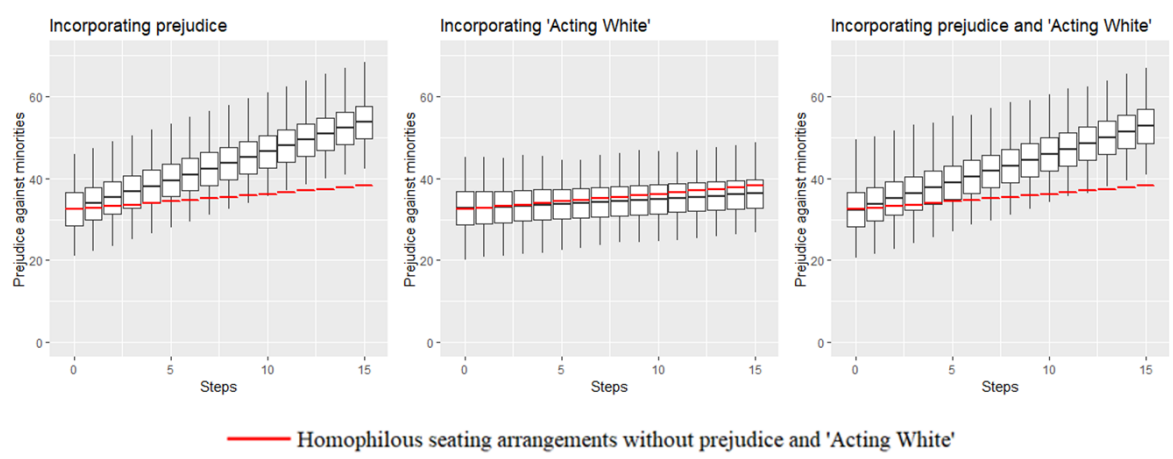

Figure 12: How prejudice and 'Acting White' modify the effect of a homophilous seating arrangement on prejudice.

\section{Sensitivity analysis}

4.11 We tested the sensitivity of our results derived from the baseline model (as described above) to (1) the number of minority agents, (2) their GPA, and (3) the extent to which deskmates influence each other.

4.12 First, we observed how increasing the initial GPA of minorities from 72 to 95 (the average GPA of majority students remained at 100) changes the results. In this new setting, the same rules still apply as in the baseline setting although the differences in the effect of seating scenarios is diminished. Thus, applying best-with-worse or heterophilous seating still reduces inequalities and the ethnic gap the most. However, the effects of these seating arrangements are weaker compared to the baseline parametrization due to smaller initial inequalities. In turn, this arrangement does not suppress talent management as much as in the baseline scenario. Finally, the different scenarios only slightly converged to each other in terms of reducing prejudice (i.e., 'best with worse' was somewhat less effective and sorted seating improved if minorities studied better).

4.13 Second, we tested how our model performs when we reduce the number of minority agents from 18 to 4 . In this case, similarly to the previous sensitivity test, the effect of seating scenarios was dampened compared to the baseline due to a lower initial level of inequalities. The most noticeable change under this sensitivity analysis was that the abilities of different seating scenarios to decrease prejudices converged to each other. For this policy, seating arrangements seem to play a determining role only when the proportion of minority students is sufficiently large. Finally, most of the seating scenarios performed similarly as in the baseline setting in terms of reducing ethnic gaps. Only when the proportion of minority students was smaller were desegregation policies somewhat less successful and homophilous seating somewhat more successful in this regard.

4.14 Finally, we tested how the results change when we decrease the weight of influence of the better achieving desk-mate from $1 / 5$ to $1 / 10$ (maintaining the weight of influence of the lower achieving desk-mate at 1/10). Unsurprisingly, we find in this sensitivity analysis that the convergence of academic outcomes is less than in the baseline scenario, thus inequalities and ethnic gaps decrease at a slower pace (except in the case of the sorted scenario). More surprisingly, not only do inequalities develop in a negative direction, but talent management 
is also depressed when lower achieving agents develop at a slower pace. This is because slowly developing disadvantaged agents hinder the development of the most talented individuals, as well (except in the case of sorted or homophilous seating arrangements when they are strongly segregated).

\section{Conclusion and Discussion}

5.1 The present paper was designed to draw attention to a potential tool for achieving certain policy objectives in the classroom. As the traditionally used desegregation policies do not seem to produce further benefits, new interventions are needed in the fight for equal opportunities and against prejudice.

5.2 Without doubt, most individual progress is due to the aspiration, motivation, effort and resources of students, and also parental and teacher influence. Nonetheless, there is considerable interest within the social sciences in estimating the impact of peers on individual outcomes (such as test scores, aggressive behavior, or even alcohol consumption). It has been documented that peers have an influence on attitudes and behavior; this impact is strong during adolescence (Sacerdote 2014) and includes attitudes toward performance and school achievement Coleman 1960, 1961, Hanushek et al.2009). Disciplines, however, differ in terms of what is meant by peer effects and how they are measured. In most studies related to the economics of education, the term peer effects is used to summarize all school or classroom effects, including class composition, teacher, peer influence, and selection effects. To date, the rich research in the economics of education has been unable to differentiate school effects from true peer effects because it has not been able to identify the sources of the latter (Lomi et al. 2011).

5.3 Furthermore, the perspective on peer effects should be backed up by an understanding of the mechanisms of peer influence. The term peer effect conceptualizes peer-originating factors that combine with the outcome variable used to provide explanations most typically in a cross-sectional setting. Peers in the classroom, however, are individuals who actively and often purposely influence the behavior and performance of one another in terms of motivation, advice, guidance, facilitation, help, persuasion, deception, and other activities and interactions. Acknowledgment of the presence of these peer-related mechanisms hence indicates a shift away from associations toward explanation, and from a cross-sectional perspective toward one involving social dynamics.

5.4 When peer influence is the focus, one needs to consider its inherently interpersonal nature, which sharply contrasts with that of class composition and school background variables. In most situations individuals are influenced by some other peers who are identifiable. Hence, one needs to find out who the relevant peers are with significant influence.

5.5 Consequentially, several studies have dealt with how peers and social networks can influence academic outcomes or prejudice (Moody 2001). Although teachers have limited scope to intervene in social networks such as friendship, they can determine seating arrangements. Deskmate assignment has been widely applied in countries where students share desks. Teachers enforce seating arrangements to facilitate their own work, to improve student academic outcomes, to encourage socially desirable behaviors, and to discourage problematic ones. Best practice strategies, however, have still not been described.

5.6 The present paper was written to provide a systematic comparison of potential strategies for improving the toolkit of teachers in the classroom and preparing them to make evidence-based interventions. More specifically, it has argued that modifying seating arrangements could represent a straightforward means of intervening to achieve policy goals such as decreasing inequality, managing talent, closing the ethnic gap in academic performance, and dampening prejudice.

5.7 In the research for this paper we modelled the potential effects of seating arrangements on academic outcomes and prejudice, but neglected the aspects of individual effort, resources, and parental and teacher influence. This is due to our primary interest in social influence, but also because of the appropriateness of the use of agent-based models for understanding social influence on academic achievement and intergroup prejudice. We also did not concentrate on other interesting outcomes beyond academic achievement and prejudice, such as disciplinary issues. As a result, we may have disregarded negative externalities that could arise following the enforcement of seating arrangements such as friction from students, parents or teachers. Enforcing such types of intervention can increase the oppositional culture in a classroom, or could create cognitive costs for students. These potential externalities further stress the importance of modeling the potential effects of seating scenarios before any actual policy is introduced.

5.8 Our study demonstrates that certain policy targets cannot be met simultaneously. Matching the best student with the worst favors the goal of decreasing inequality. Assigning deskmates who are as different as possible 
decreases the overall level of prejudice and closes the ethnic gap in academic performance. In contrast, making the best students sit together with similarly good students or allowing them to choose their own deskmates is beneficial in terms of talent management.

5.9 Previous studies have argued that even desegregation at the system and school level will result in within-classroom separation due to homophilous pair selection (Moody 2001). Students left alone to decide about their partners (including friendship or deskmate selection) will interact with others who are similar to them. This process creates obstacles to interaction between students with different levels of academic performance or ethnic background (Lau \& Murnighan 1998. Some scholars have drawn attention to the fact that subgroup polarization can be overcome if crisscrossing agents exist who share demographic attributes with several subgroups. The dual membership status of these crisscrossing agents enables them to mediate between different social groups and through this prevents polarization (Evans-Pritchard 1954, Mäs et al. 2013: Simmel 1908). The crisscrossing agents in the context of our model are (1) minority students with a high GPA and (2) majority students with a low GPA. Our simulation has provided evidence that the role of these agents is substantial in academic outcomes and fighting prejudice.

5.10 We have also shown that there are two phenomena that block crisscrossing agents from bridging faultlines: prejudice, and 'Acting White'. Our simulations highlighted that these phenomena can slow down social convergence. Hence, efforts that reduce such tendencies could be helpful in general and could also further improve the efficiency of the application of seating policies.

5.11 To sum up, the model presented here involves the application of social influence and opinion dynamics models to study fundamental problems in education at the micro level. It illustrates how existing models can be applied to serious problems and dilemmas in a specific context, and indicates how model results could contribute to social policy recommendations for improving academic outcomes and decreasing prejudice in the classroom. Furthermore, the study supplemented previous research by taking into account pre-existing prejudice and the exclusion of better performing minority students by other minority members; that is, the 'Acting White' phenomenon. The introduction of these phenomena creates a more realistic scenario for understanding homophilous seating arrangements, thereby increasing the external validity of the model and taking a further step from theory to real-life application.

\section{Acknowledgements}

This project has received funding from the European Research Council (ERC) under the European Union's Horizon 2020 research and innovation programme (grant agreement no 648693).

\section{Model Documentation}

The model has been implemented in NetLogo (Wilensky|1999). The code is available at: https: //www . comses . net/codebases/dc5a18a1-493a-4434-af26-680ade94a313/releases/1.0.0/

\section{Appendix}


Increasing the initial GPA of minority students from 72 to 95
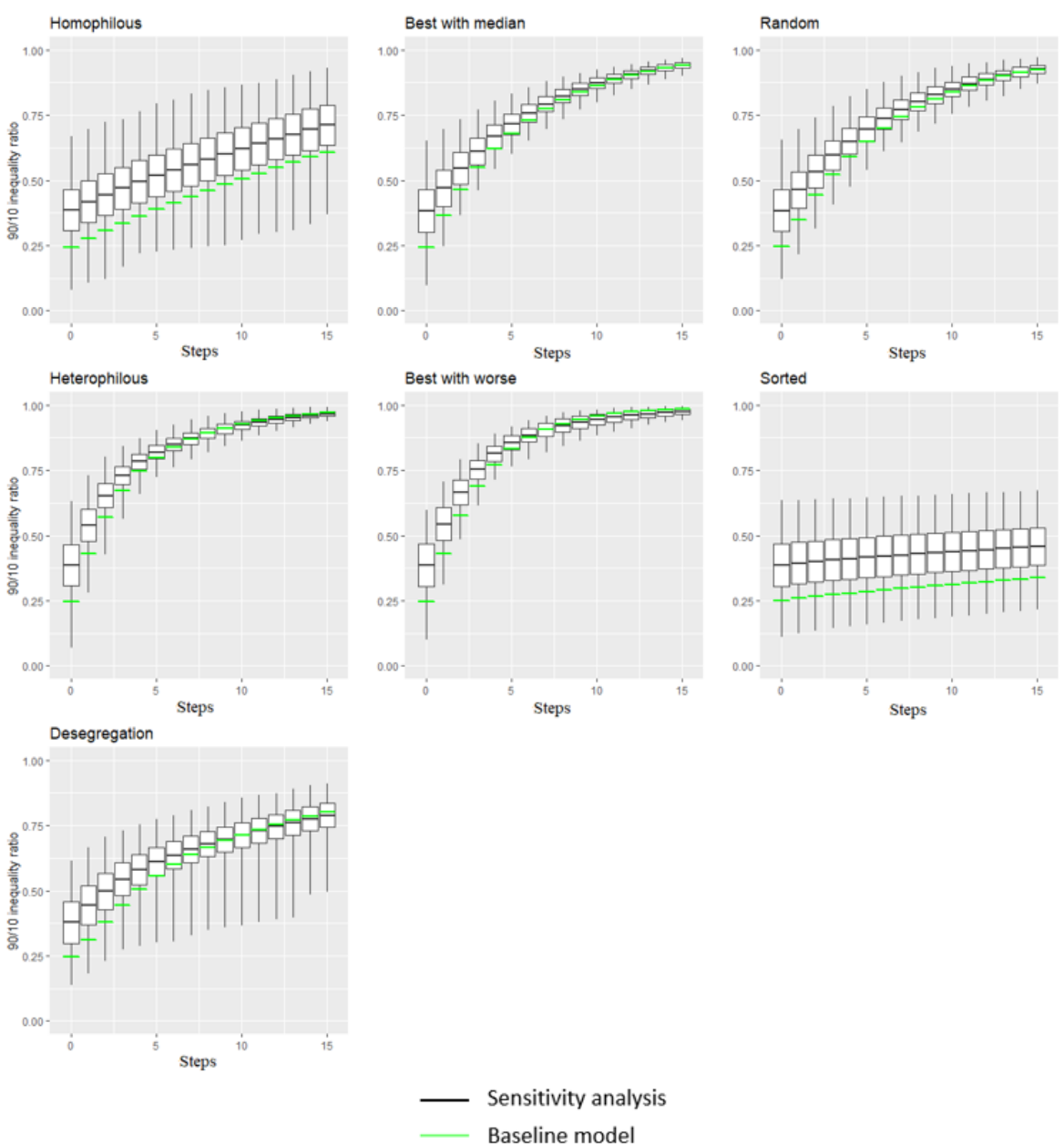

Figure 13: How increasing the initial GPA of minority students modifies the effect of seating arrangements on inequality.
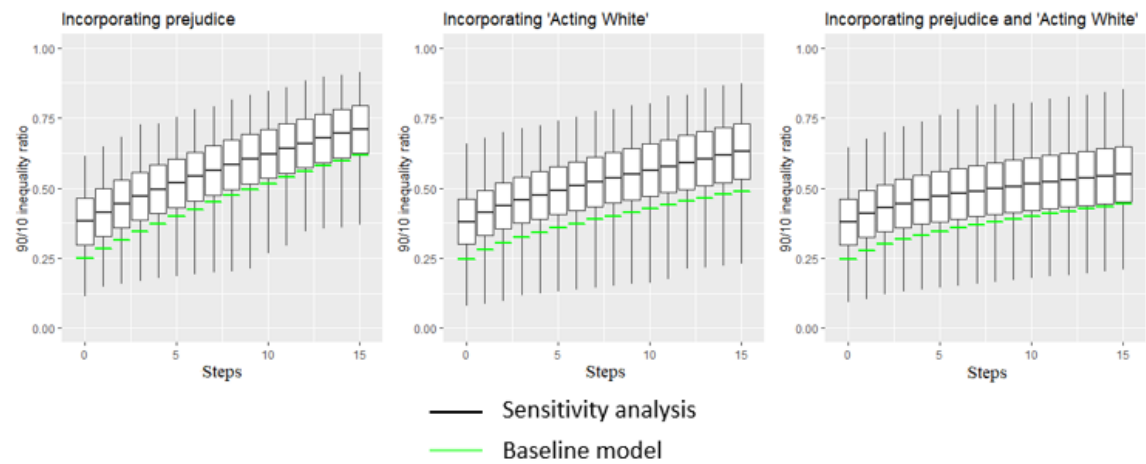

Figure 14: How increasing the initial GPA of minority students modifies the effect of homophilous seating arrangements (with and without prejudice and 'Acting White') on inequality. 

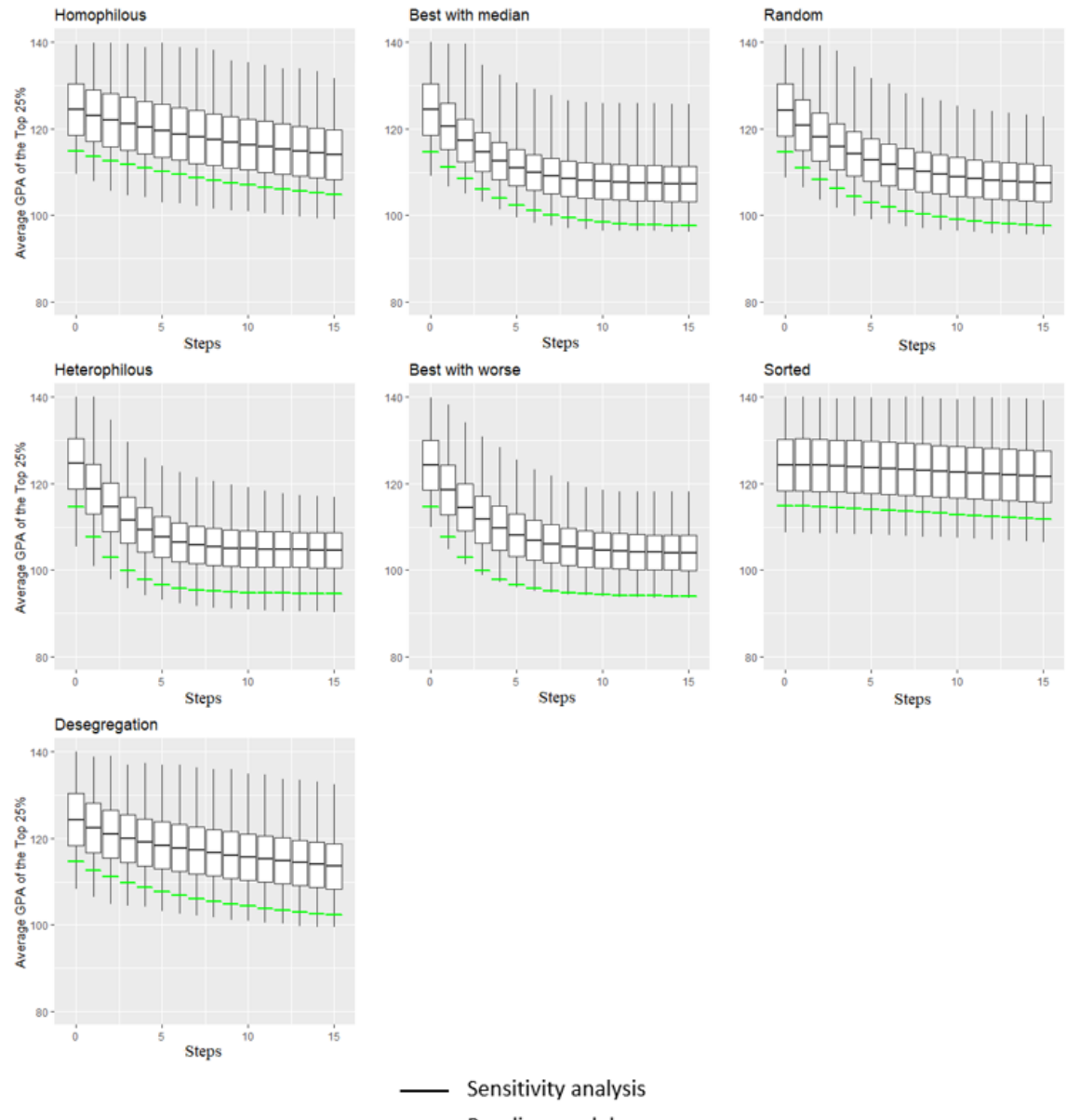

Baseline model

Figure 15: How increasing the initial GPA of minority students modifies the effect of seating arrangements on talent management.
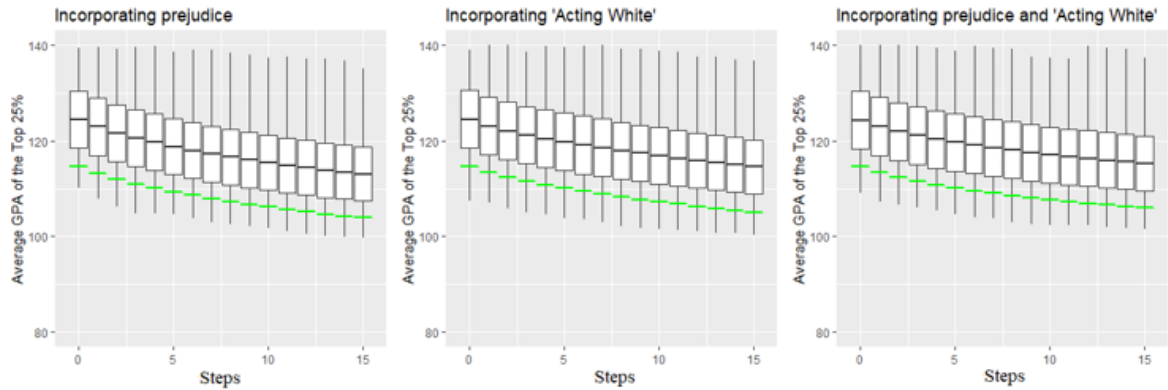

- Sensitivity analysis

Baseline model

Figure 16: How increasing the initial GPA of minority students modifies the effect of seating arrangements on talent management. 

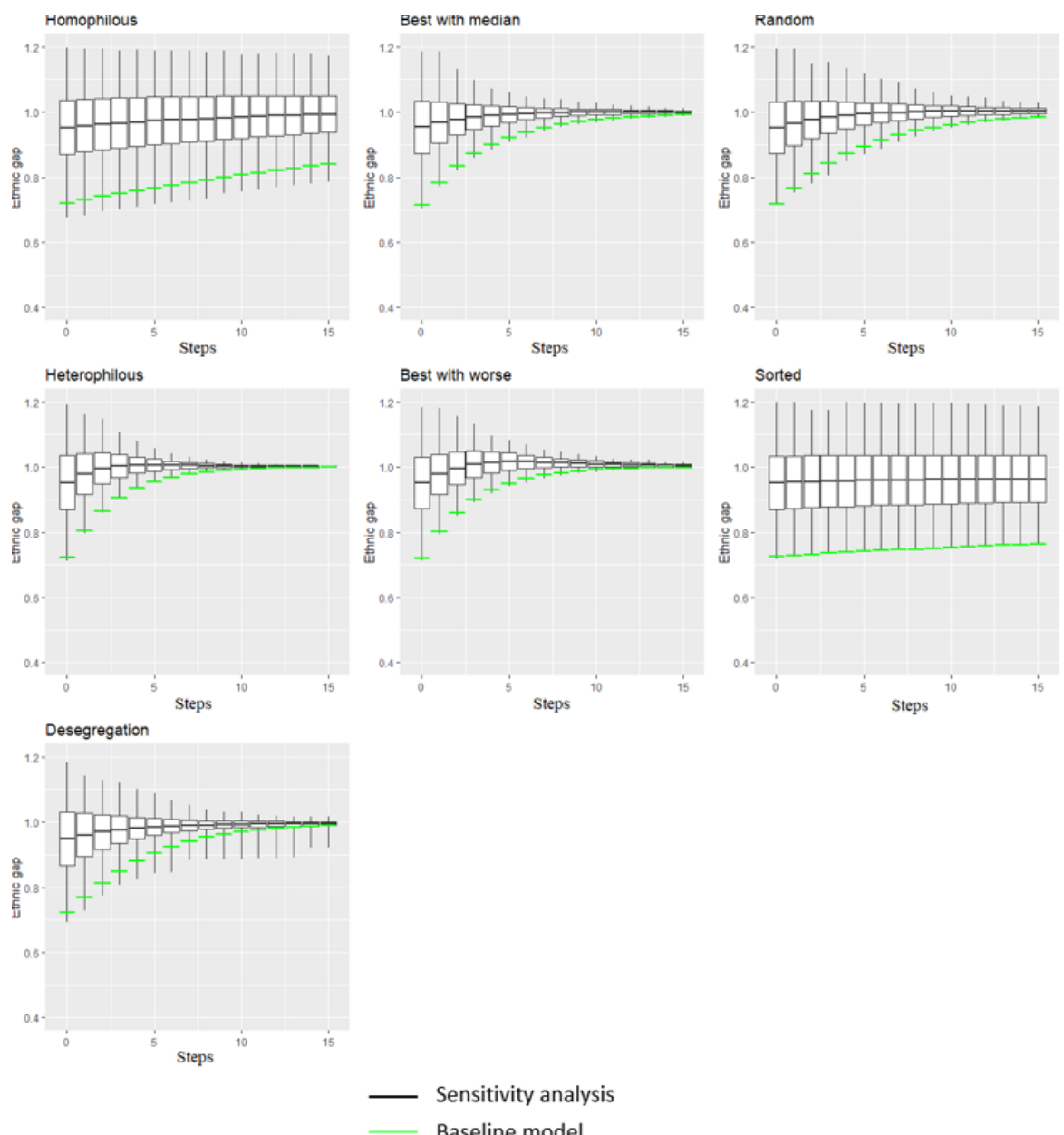

Figure 17: How increasing the initial GPA of minority students modifies the effect of homophilous seating arrangements (with and without prejudice and 'Acting White') on talent management.
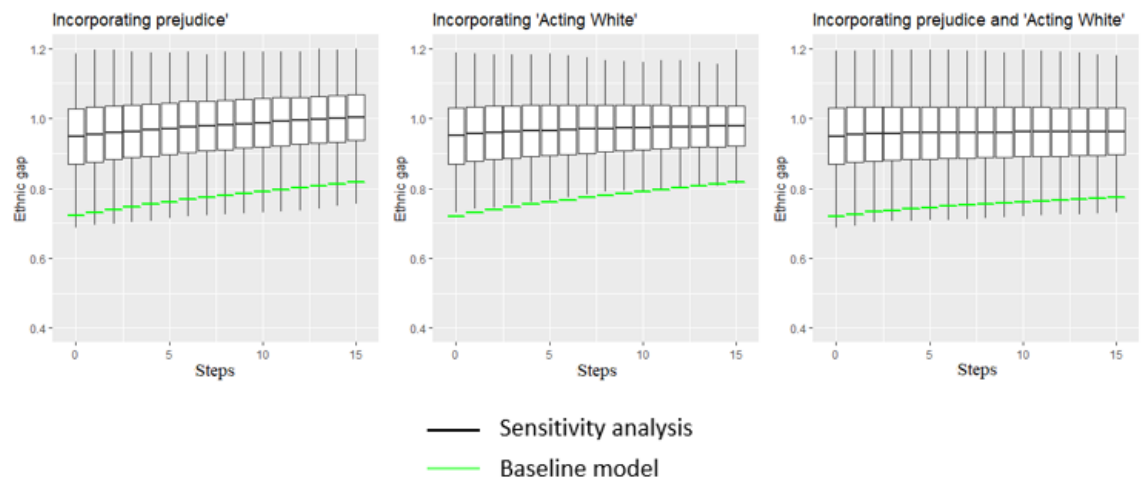
the ethnic gap. 

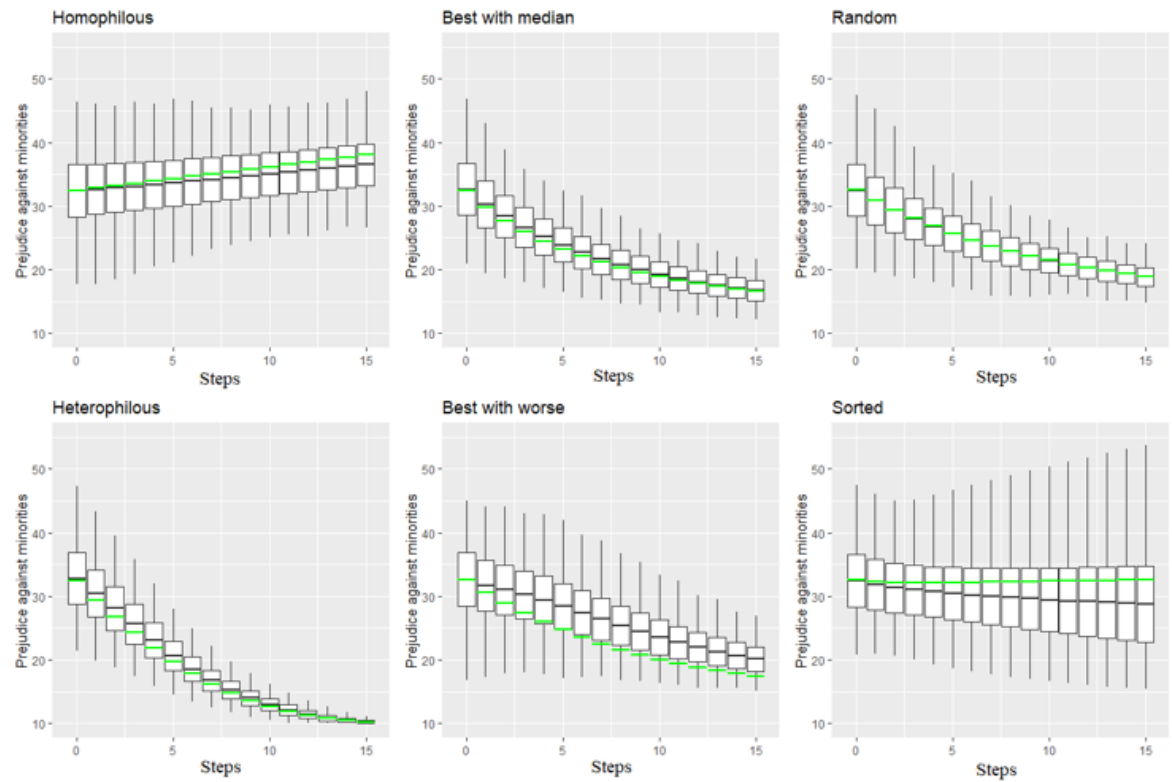

Best with worse

Sorted
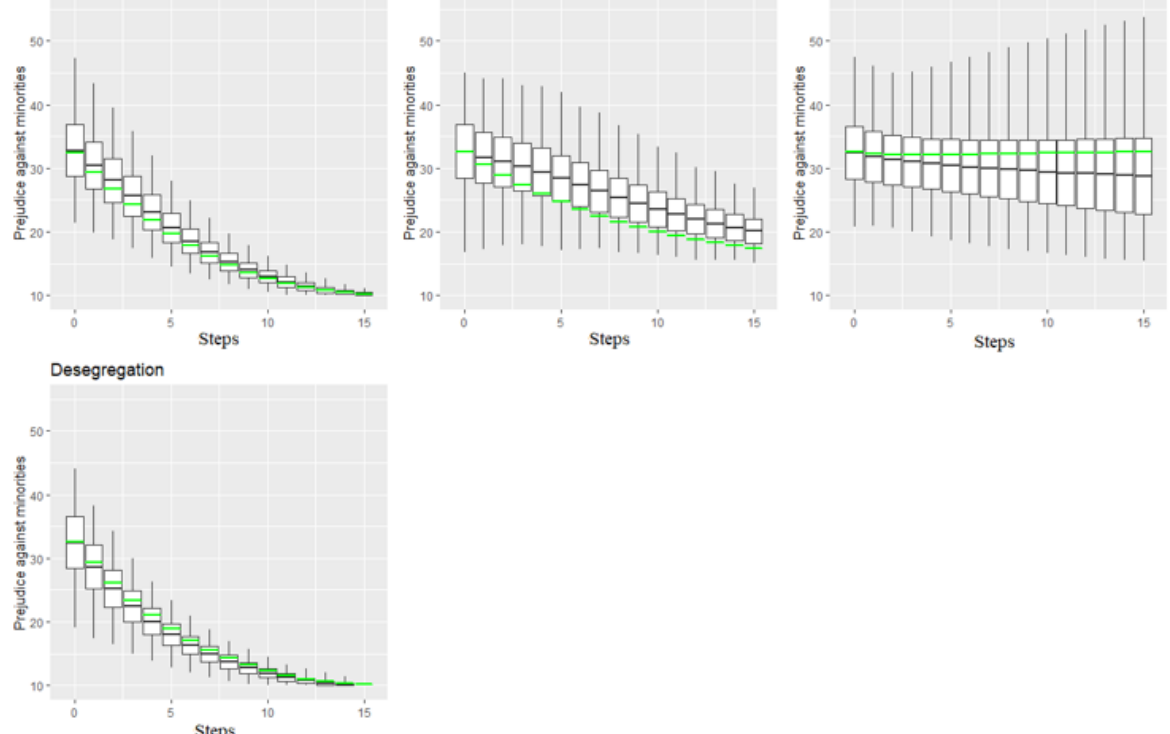

Sensitivity analysis

Baseline model

Figure 19: How increasing the initial GPA of minority students modifies the effect of homophilous seating arrangements (with and without prejudice and 'Acting White') on ethnic gap.
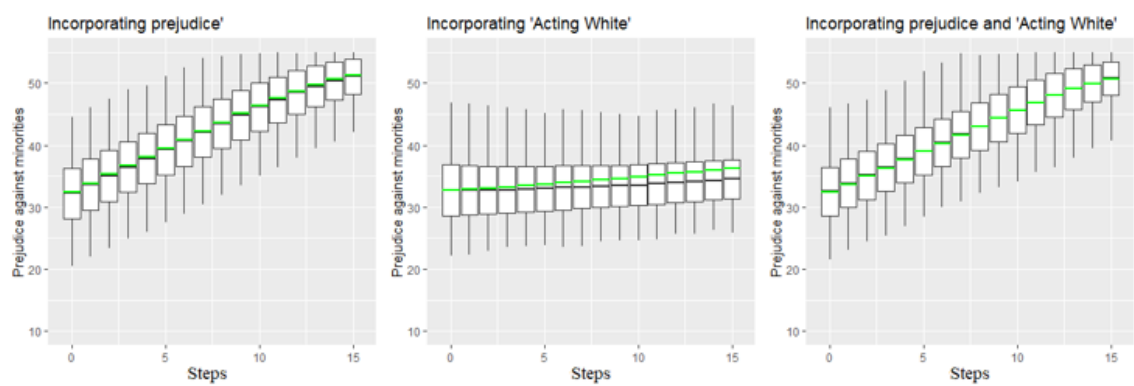

_ Sensitivity analysis
Baseline model

Figure 20: How increasing the initial GPA of minority students modifies the effect of seating arrangements on prejudice. 

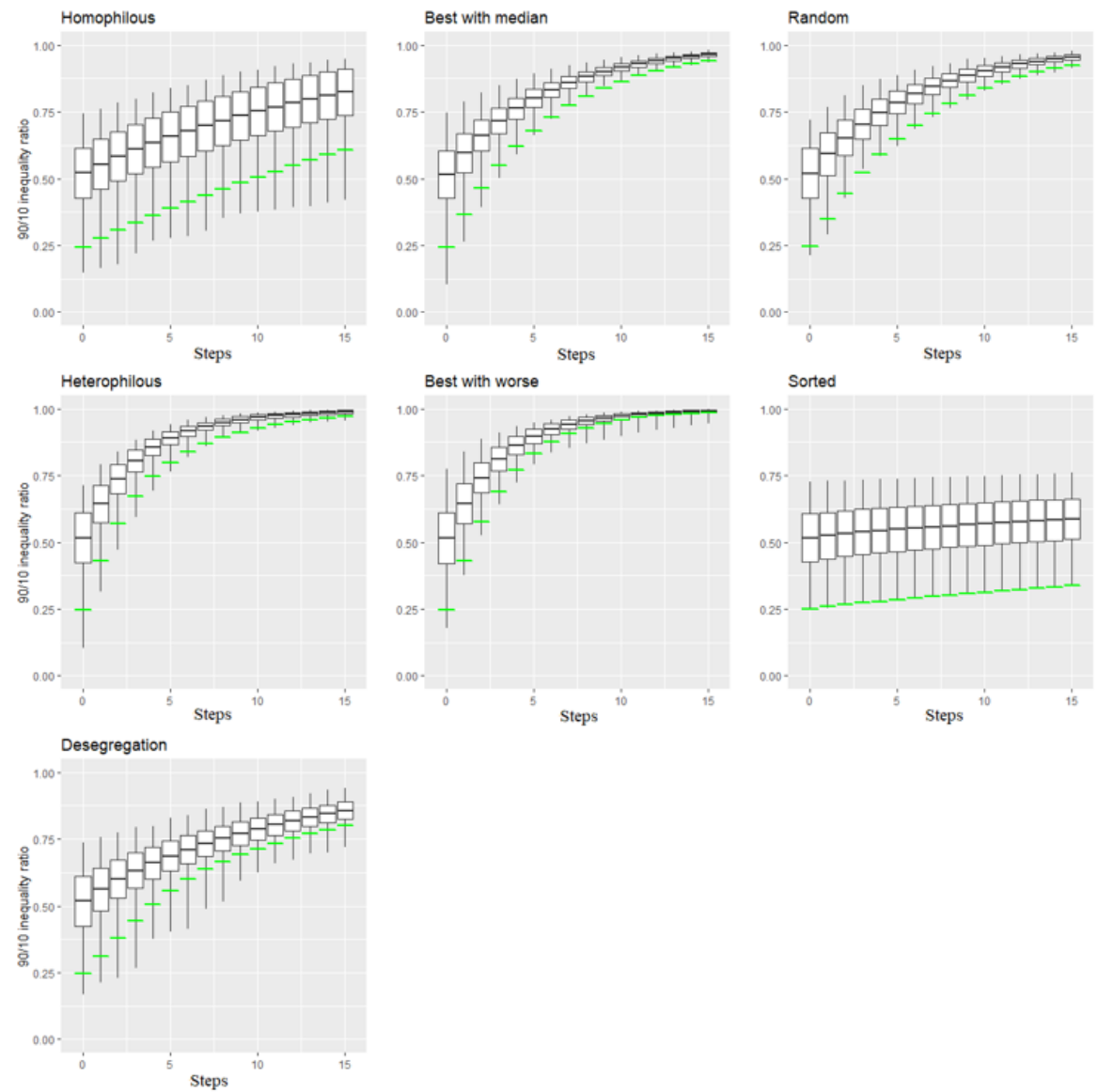

- Sensitivity analysis
Baseline model

Figure 21: How increasing the initial GPA of minority students modifies the effect of homophilous seating arrangements (with and without prejudice and 'Acting White') on prejudice.

\section{Decreasing the number of minority students from 18 to 4}
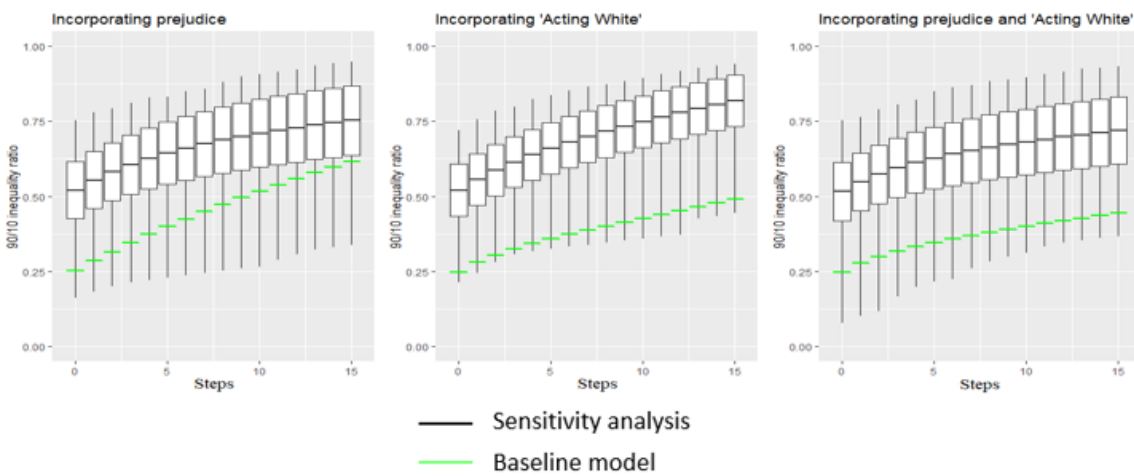

Baseline mode

Figure 22: How decreasing the proportion of minority students modifies the effect of seating arrangements on inequality. 

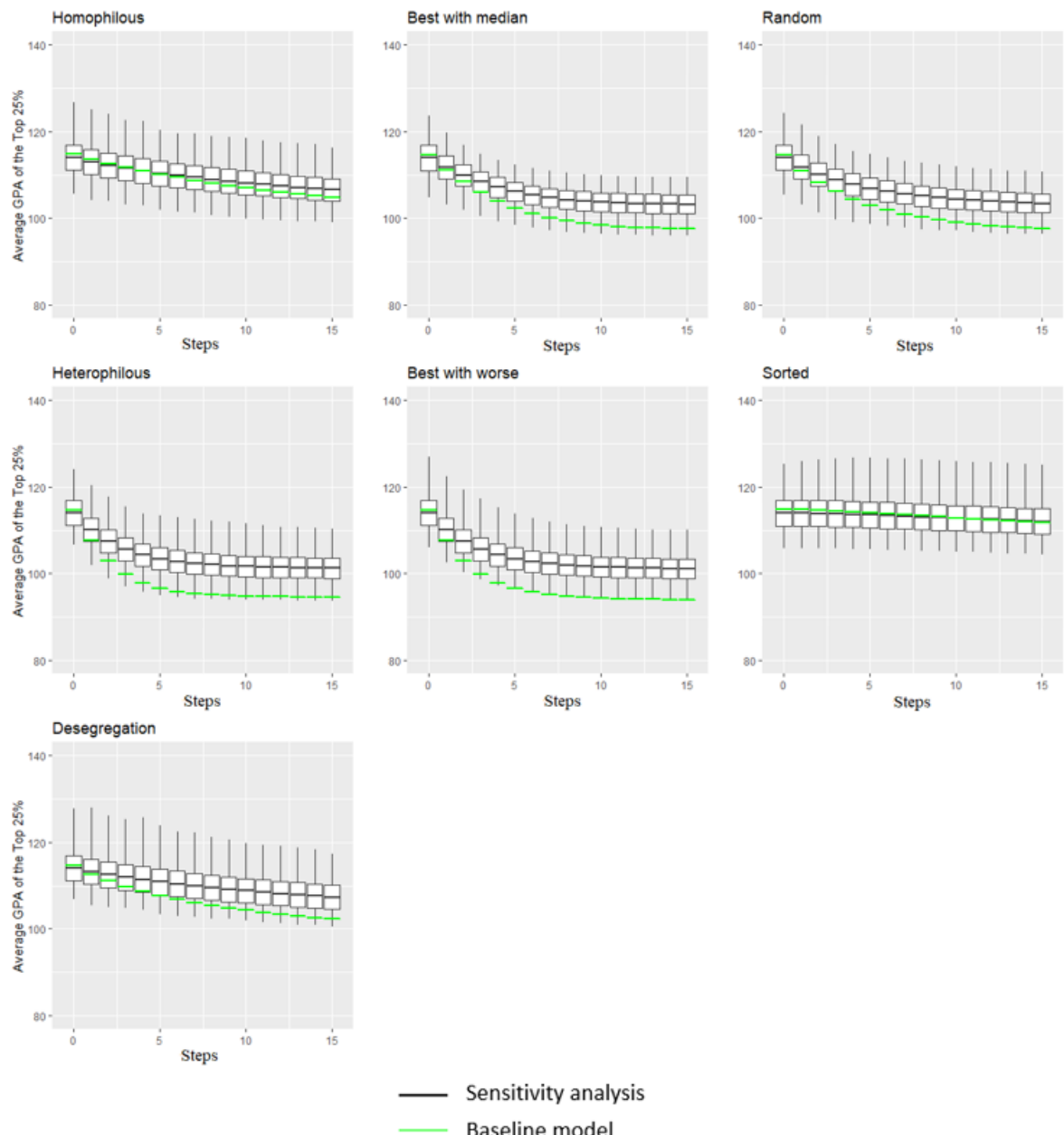

Figure 23: How decreasing the proportion of minority students modifies the effect of homophilous seating arrangements (with and without prejudice and 'Acting White') on inequality.
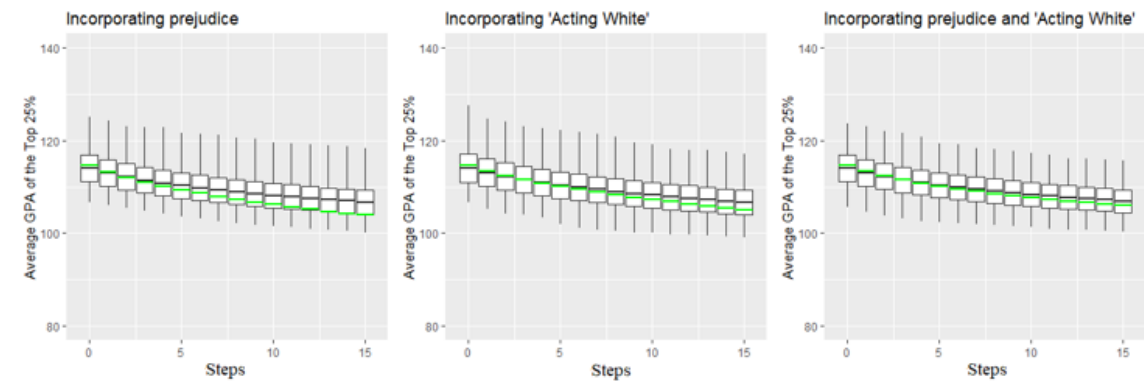

Sensitivity analysis

Baseline model

Figure 24: How decreasing the proportion of minority students modifies the effect of seating arrangements on talent management. 

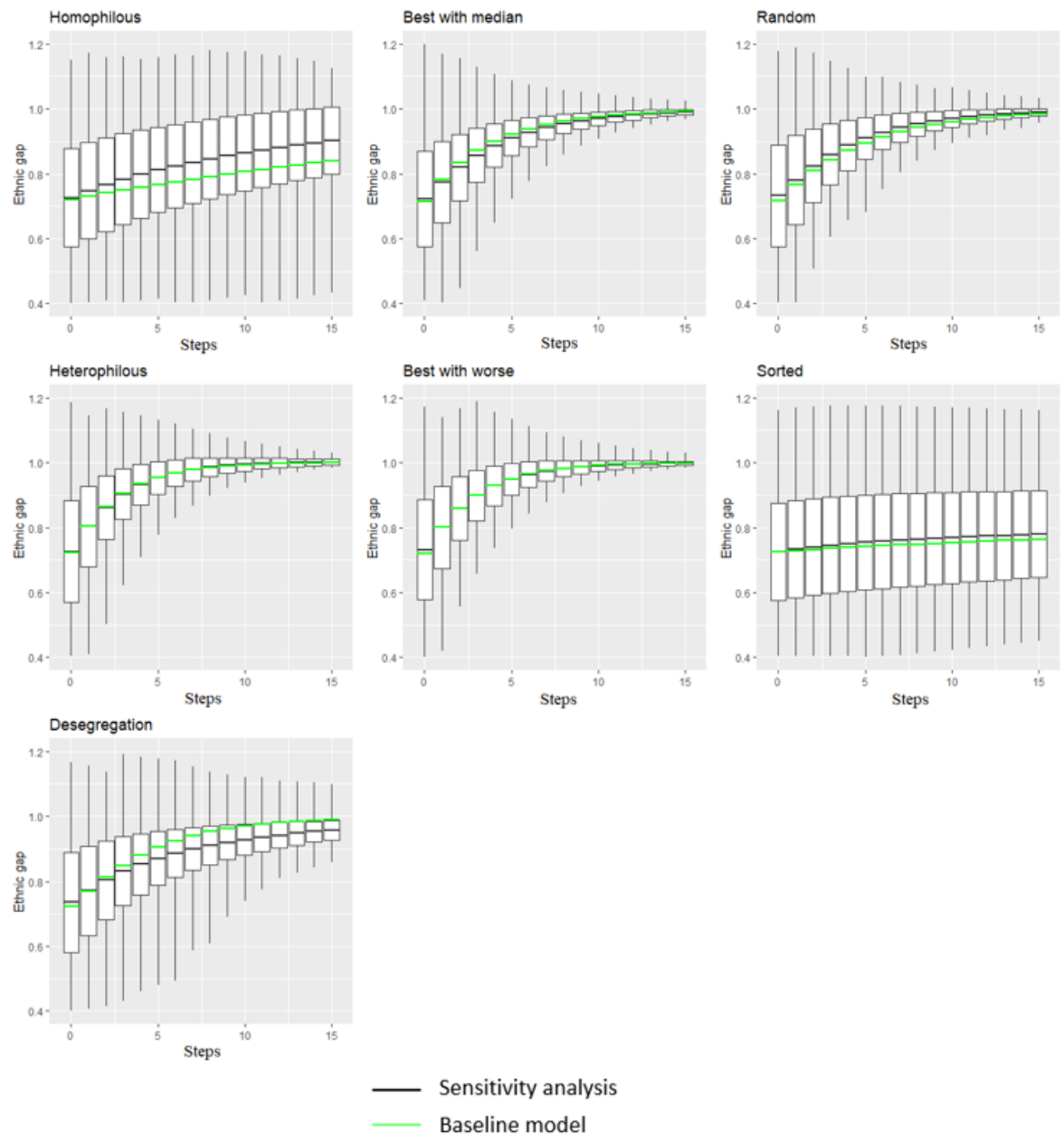

Figure 25: How decreasing the proportion of minority students modifies the effect of homophilous seating arrangements (with and without prejudice and 'Acting White') on talent management.
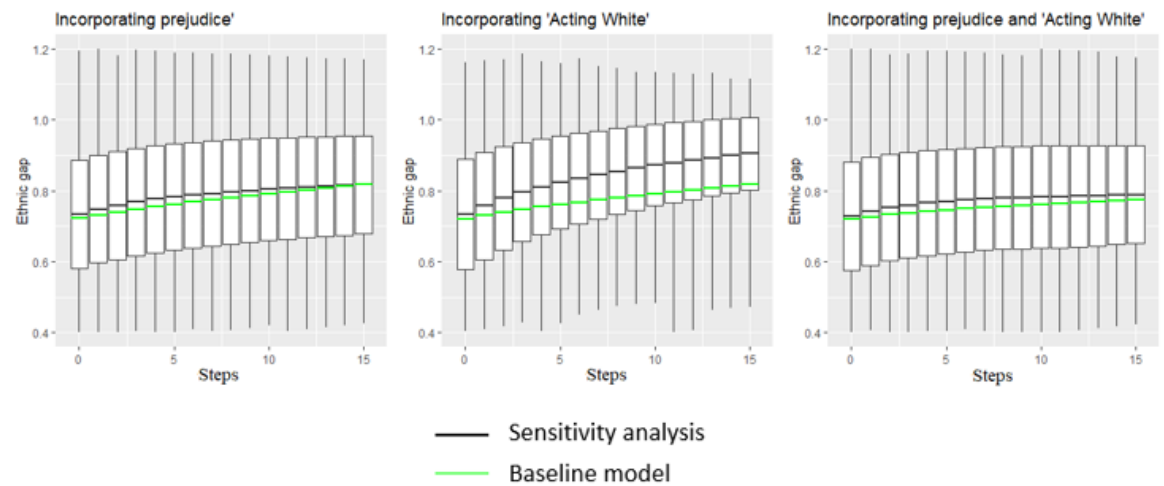

Figure 26: How decreasing the proportion of minority students modifies the effect of homophilous seating arrangements (with and without prejudice and 'Acting White') on ethnic gap. 

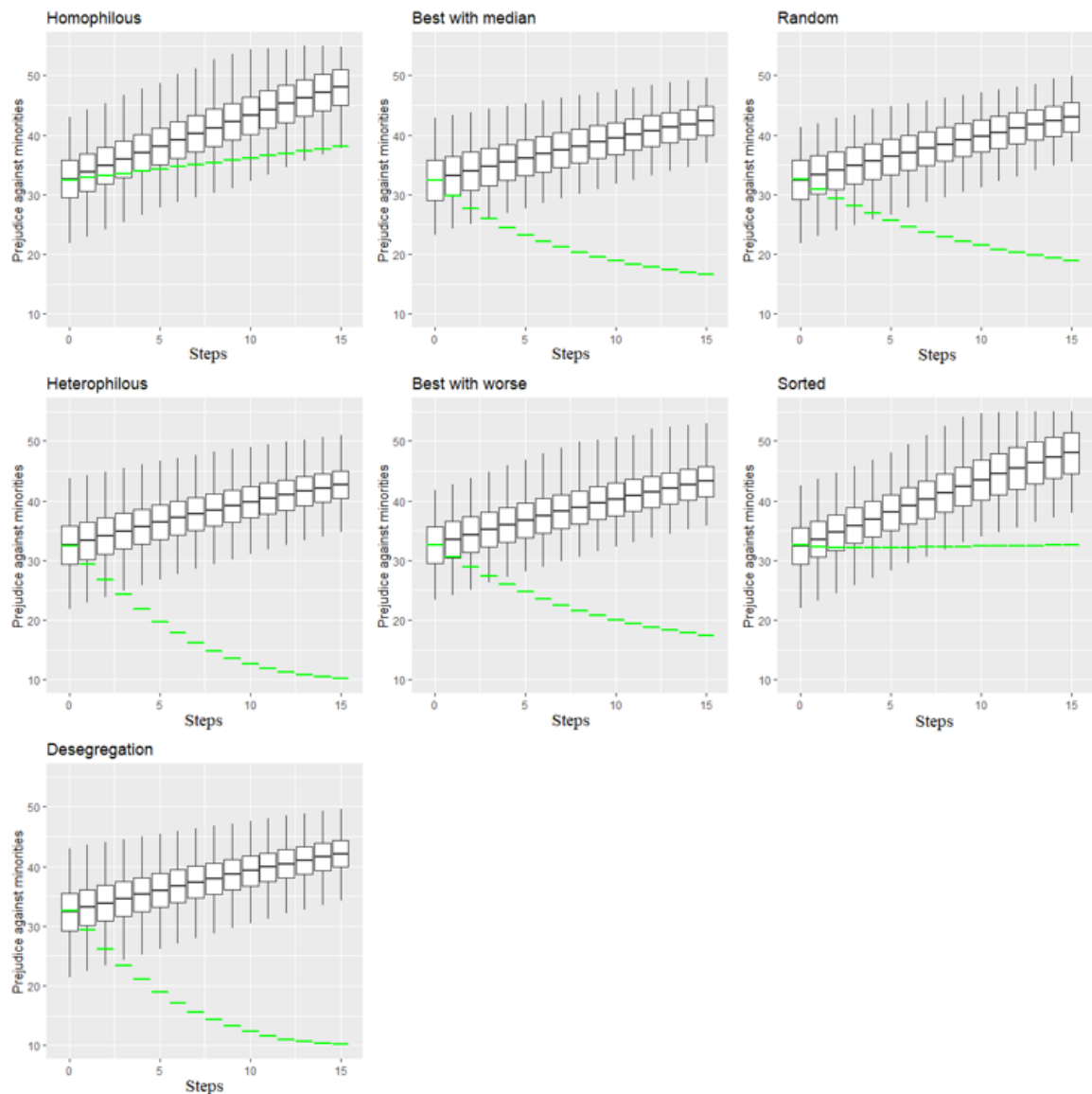

- Sensitivity analysis

Baseline model

Figure 27: How decreasing the proportion of minority students modifies the effect of seating arrangements on prejudice.
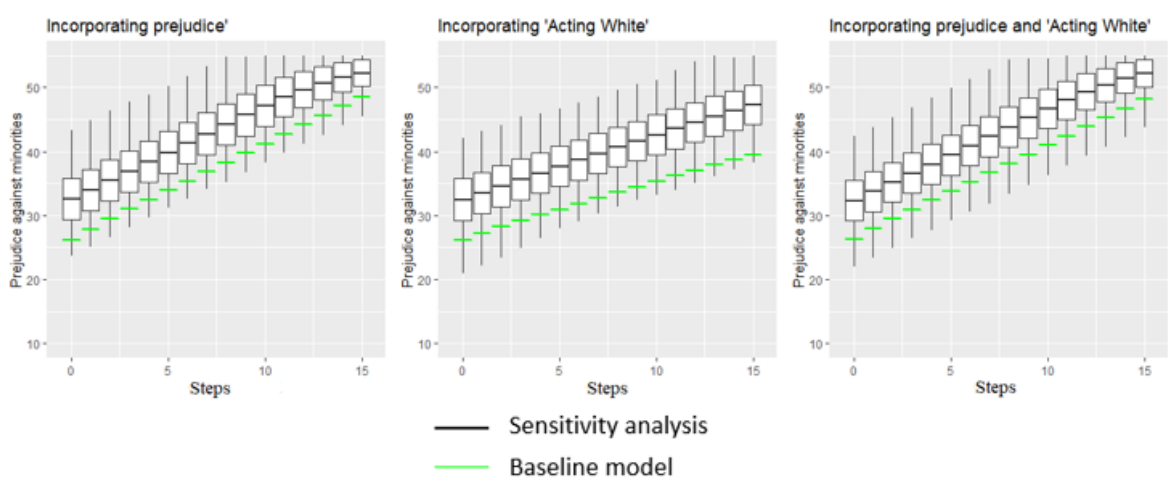

Figure 28: How decreasing the proportion of minority students modifies the effect of homophilous seating arrangements (with and without prejudice and 'Acting White') on prejudice. 

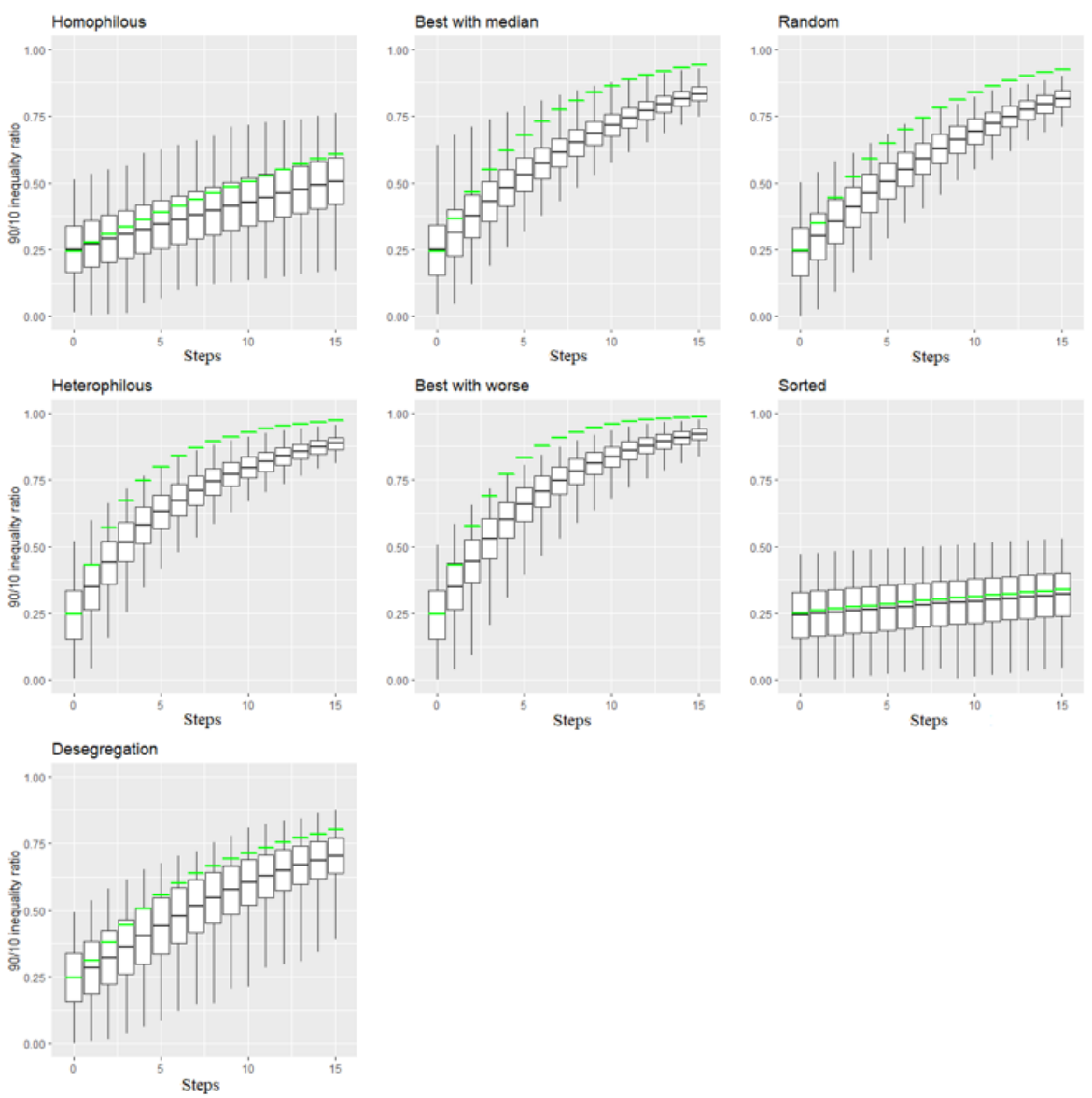

Sensitivity analysis

Baseline model

Figure 29: How decreasing the weight of the influence of better achieving desk-mates modifies the effect of seating arrangements on inequality.
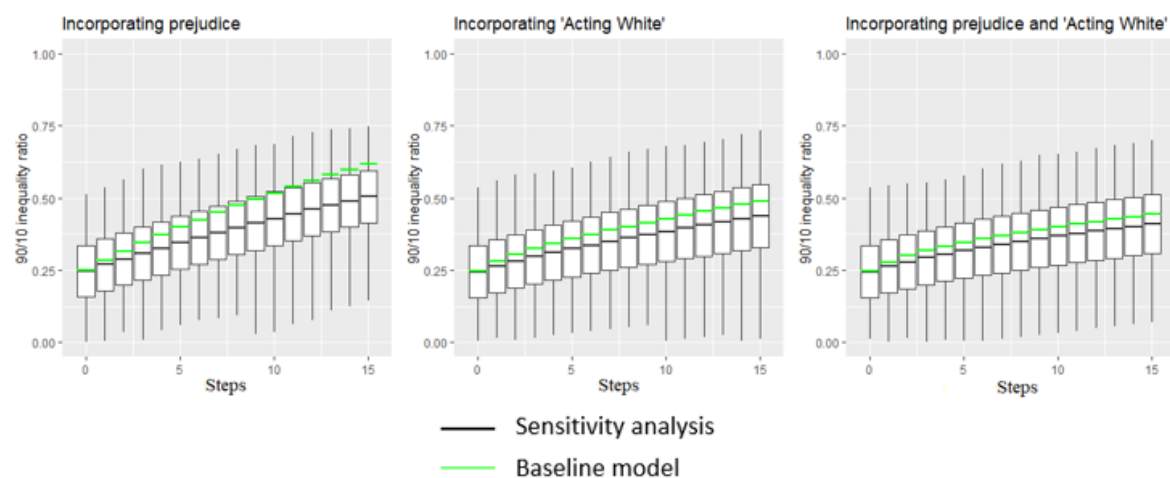

Figure 30: How decreasing the weight of the influence of better achieving desk-mates modifies the effect of homophilous seating arrangements (with and without prejudice and 'Acting White') on inequality. 

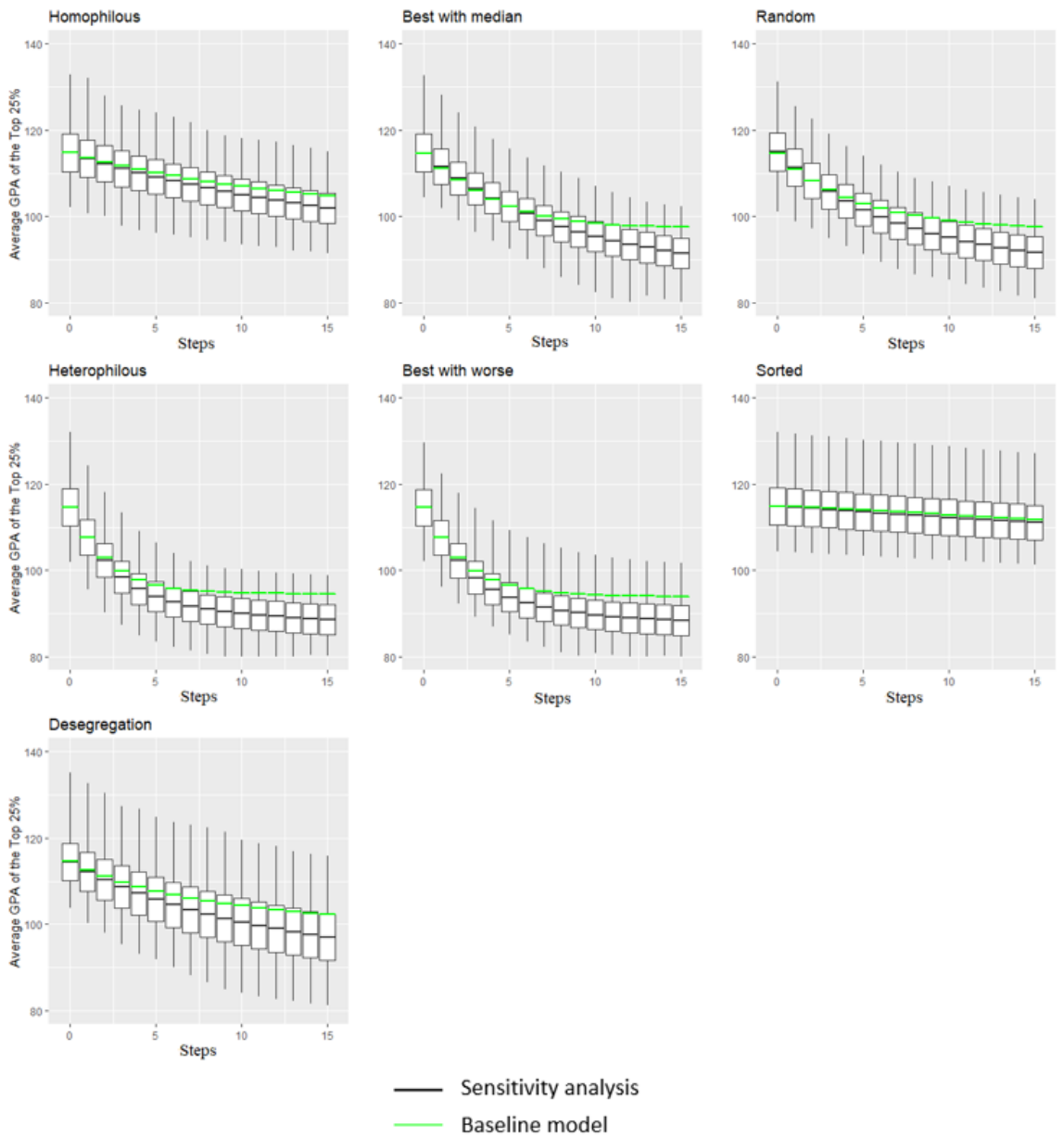

Figure 31: How decreasing the weight of the influence of better achieving desk-mates modifies the effect of seating arrangements on talent management.
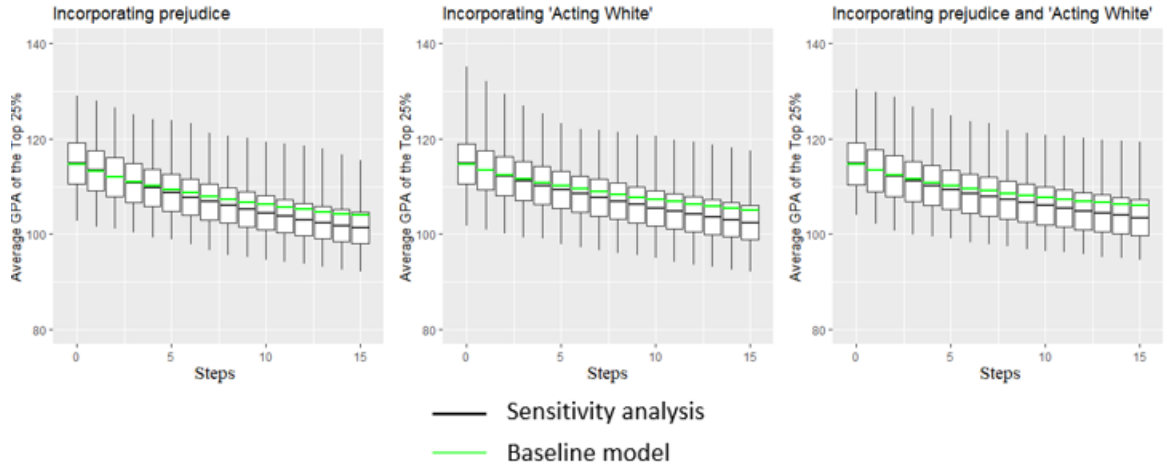

Figure 32: How decreasing the weight of the influence of better achieving desk-mates modifies the effect of homophilous seating arrangements (with and without prejudice and 'Acting White') on talent management. 

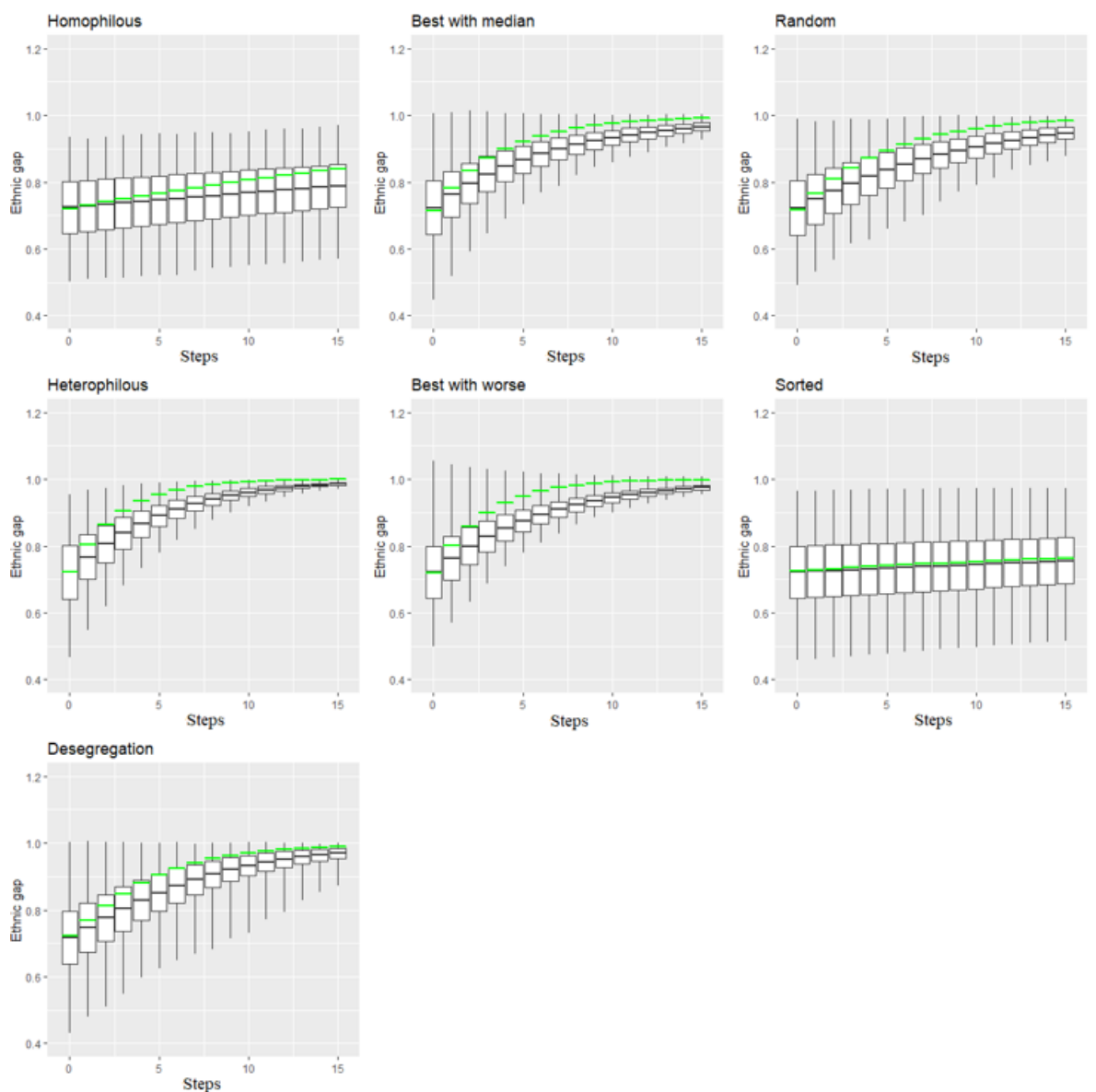

Sensitivity analysis

Baseline model

Figure 33: How decreasing the weight of the influence of better achieving desk-mates modifies the effect of seating arrangements on the ethnic gap.
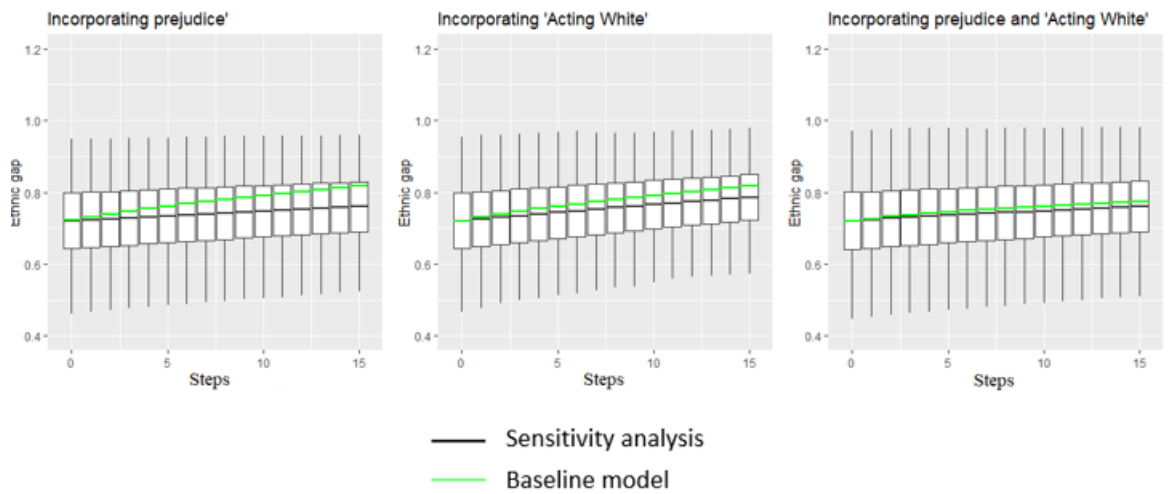

Figure 34: How decreasing the weight of the influence of better achieving desk-mates modifies the effect of homophilous seating arrangements (with and without prejudice and 'Acting White') on ethnic gap. 

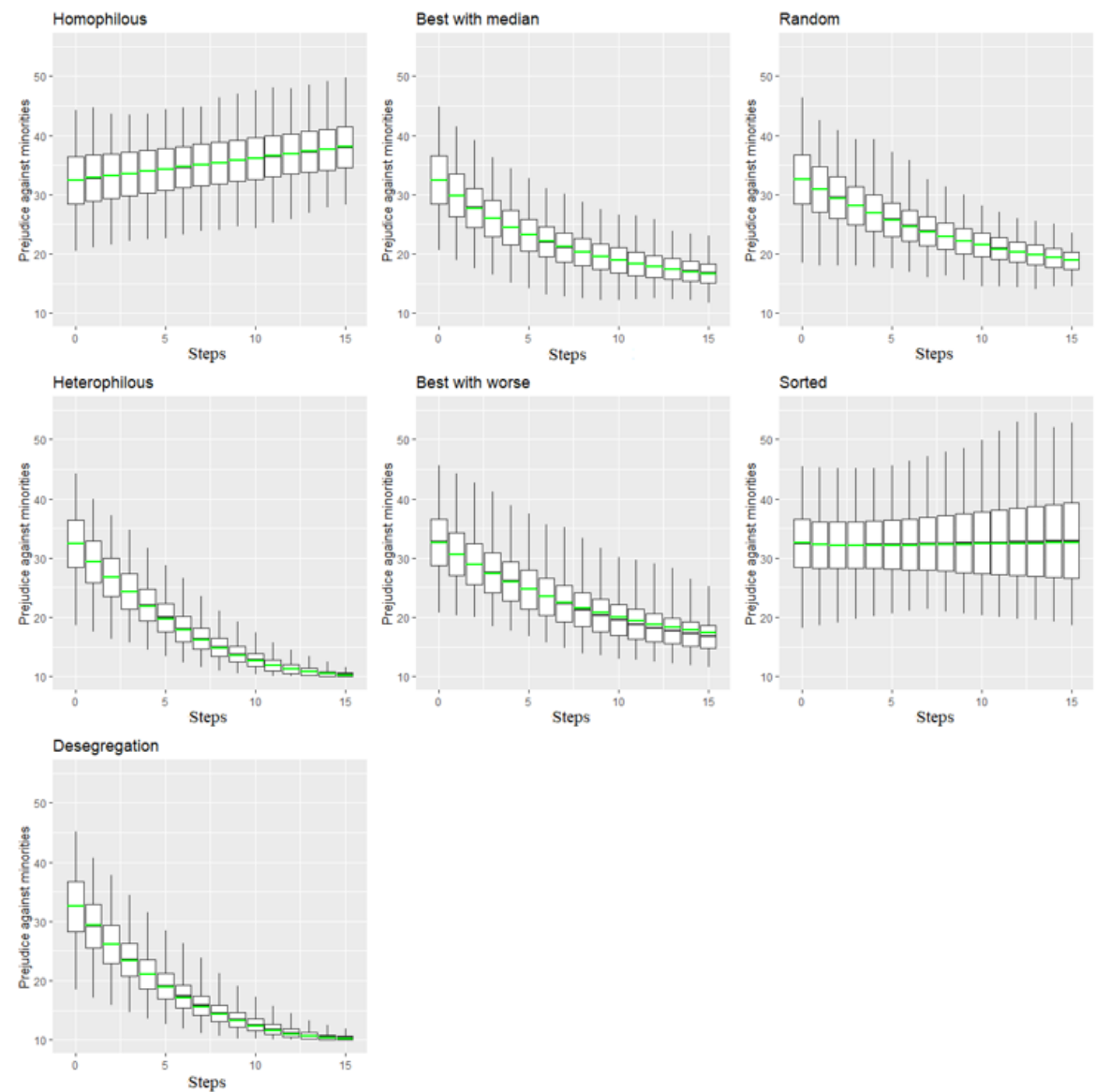

L Sensitivity analysis
Baseline model

Figure 35: How decreasing the weight of the influence of better achieving desk-mates modifies the effect of seating arrangements on prejudice.
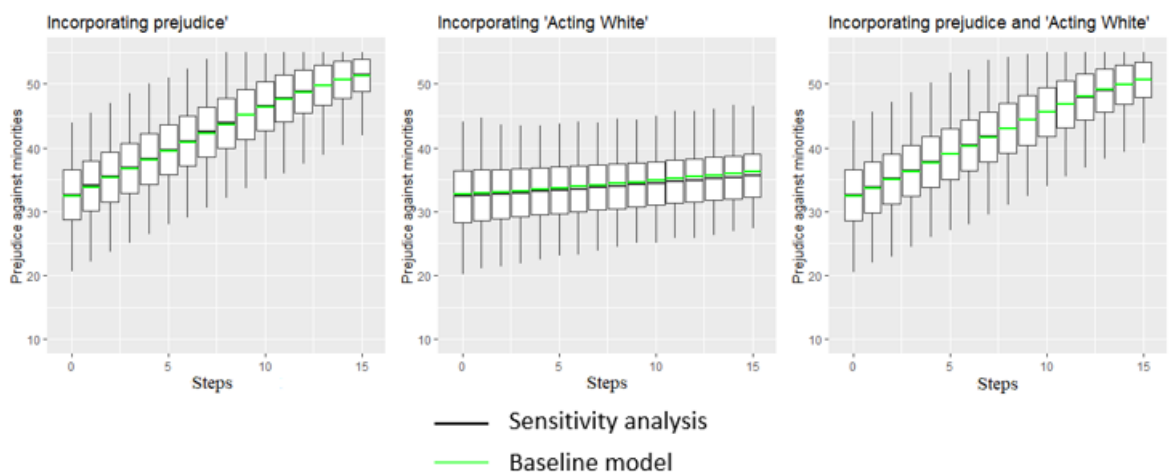

Figure 36: How decreasing the weight of the influence of better achieving desk-mates modifies the effect of homophilous seating arrangements (with and without prejudice and 'Acting White') on prejudice.

\section{References}

Aboud, F. E. (2005). The development of prejudice in childhood and adolescence. In J. F. Dovidio, P. E. Glick \& L. A. Rudman (Eds.), On the Nature of Prejudice, (pp. 310-326). Oxford: Blackwell 
Ainsworth-Darnell, J. W. \& Downey, D. B. (1998). Assessing the oppositional culture explanation for racial/ethnic differences in school performance. American Sociological Review, 63(4), 536-553

Allport, G. W. (1958). The Nature of Prejudice. New York, NY: Doubleday

Back, M. D., Schmukle, S. C. \& Egloff, B. (2008). Becoming friends by chance. Psychological Science, 19(5), 439

Bar-Tal, D. \& Teichman, Y. (2009). Stereotypes and Prejudice in Conflict: Representations of Arabs in Israeli Jewish Society. Cambridge: Cambridge University Press

Benedict, M. E. \& Hoag, J. (2004). Seating location in large lectures: Are seating preferences or location related to course performance? Journal of Economic Education, 35(3), 215-231

Boda, Z. (2018). Social influence on observed race. Sociological Science, 5, 29-57

Boda, Z. \& Néray, B. (2015). Inter-ethnic friendship and negative ties in secondary school. Social Networks, 43 , $57-72$

Brown, R. (2011). Prejudice: Its Social Psychology. Chichester: Wiley

Brown, R., Eller, A., Leeds, S. \& Stace, K. (2007). Intergroup contact and intergroup attitudes: A longitudinal study. European Journal of Social Psychology, 37(4), 692-703

Buckalew, L. W., Daly, J. D. \& Coffield, K. E. (1986). Relationship of initial class attendance and seating location to academic performance in psychology classes. Bulletin of the Psychonomic Society, 24(1), 63-64

Caldas, S. J. \& Bankston III, C. (1998). The inequality of separation: Racial composition of schools and academic achievement. Educational Administration Quarterly, 34(4), 533-557

Card, D. \& Rothstein, J. (2007). Racial segregation and the black-white test score gap. Journal of Public Economics, 91(11-12), 2158-2184

Carley, K. (1991). A theory of group stability. American Sociological Review, 56(3), 331-354

Coleman, J. S. (1960). The adolescent subculture and academic achievement. American Journal of Sociology, 65(4), 337-347

Coleman, J. S. (1961). The Adolescent Society: The Social Life of the Teenager and Its Impact on Education. New York, NY: Free Press

Coleman, J. S. (1966). Equality of educational opportunity. Integrated Education, 6(5), 19-28

Cook, P. J. \& Ludwig, J. (1997). Weighing the "burden of 'acting white' ": Are there race differences in attitudes toward education? Journal of Policy Analysis and Management, 16(2), 256-278

Crain, R. L. \& Mahard, R. E. (1978). Desegregation and black achievement: A review of the research. Law and Contemporary Problems, 42, 17

Dandekar, P., Goel, A. \& Lee, D. T. (2013). Biased assimilation, homophily, and the dynamics of polarization. Proceedings of the National Academy of Sciences of the United States of America, 110(15), 5791-5796

Davies, K., Tropp, L. R., Aron, A., Pettigrew, T. F. \& Wright, S. C. (2011). Cross-group friendships and intergroup attitudes: A meta-analytic review. Personality and Social Psychology Review, 15(4), 332-351

De Klepper, M., Sleebos, E., Van de Bunt, G. \& Agneessens, F. (2010). Similarity in friendship networks: Selection or influence? The effect of constraining contexts and non-visible individual attributes. Social Networks, 32(1), $82-90$

Deffuant, G., Neau, D., Amblard, F. \& Weisbuch, G. (2000). Mixing beliefs among interacting agents. Advances in Complex Systems, 3(01n04), 87-98

DeGroot, M. H. (1974). Reaching a consensus. Journal of the American Statistical Association, 69(345), 118-121

DellaPosta, D., Shi, Y. \& Macy, M. (2015). Why do liberals drink lattes? American Journal of Sociology, 120(5), 1473-1511 
Dovidio, J. F., Eller, A. \& Hewstone, M. (2011). Improving intergroup relations through direct, extended and other forms of indirect contact. Group Processes and Intergroup Relations, 14(2), 147-160

Evans-Pritchard, E. E. (1954). The Institutions of Primitive Societies: A Series of Broadcast Talks. Oxford: Basil Blackwell

Farmer, T. W. (2000). The social dynamics of aggressive and disruptive behavior in school: Implications for behavior consultation. Journal of Educational and Psychological Consultation, 11(3-4), 299-321

Farmer, T. W., Goforth, J. B., Hives, J., Aaron, A., Jackson, F. \& Sgammato, A. (2006). Competence enhancement behavior management. Preventing School Failure: Alternative Education for Children and Youth, 50(3), 39-44

Feddes, A. R., Noack, P. \& Rutland, A. (2009). Direct and extended friendship effects on minority and majority children's interethnic attitudes: A longitudinal study. Child Development, 80(2), 377-390

Fields, J. M. \& Schuman, H. (1976). Public beliefs about the beliefs of the public. Public Opinion Quarterly, 40(4), 427-448

Flache, A., Mäs, M., Feliciani, T., Chattoe-Brown, E., Deffuant, G., Huet, S. \& Lorenz, J. (2017). Models of social influence: Towards the next frontiers. Journal of Artificial Societies and Social Simulation, 20(4), 2

Flashman, J. (2012). Different preferences or different opportunities? Explaining race differentials in the academic achievement of friends. Social Science Research, 41(4), 888-903

Flashman, J. (2014). Friend effects and racial disparities in academic achievement. Sociological Science, 1, 260276

Fordham, S. \& Ogbu, J. U. (1986). Black students' school success: Coping with the "burden of 'acting white' ". The Urban Review, 18(3), 176-206

Fortuin, J., Geel, M. v. \& Vedder, P. (2016). Peers and academic achievement: A longitudinal study on selection and socialization effects of in-class friends. Journal of Educational Research, 109(1), 1-6

Friedkin, N. E. \& Johnsen, E. C. (1990). Social influence and opinions. Journal of Mathematical Sociology, 15(3-4), 193-206

Friedkin, N. E. \& Johnsen, E. C. (1997). Social positions in influence networks. Social Networks, 19(3), 209-222

Fryer Jr., R. G. \& Torelli, P. (2010). An empirical analysis of 'acting white'. Journal of Public Economics, 94(5-6), 380-396

Gest, S. D. \& Rodkin, P. C. (2011). Teaching practices and elementary classroom peer ecologies. Journal of Applied Developmental Psychology, 32(5), 288-296

Gremmen, M. C., Dijkstra, J. K., Steglich, C. \& Veenstra, R. (2017). First selection, then influence: Developmental differences in friendship dynamics regarding academic achievement. Developmental Psychology, 53(7), 1356

Gremmen, M. C., Van den Berg, Y. H. M., Steglich, C., Veenstra, R. \& Dijkstra, J. K. (2018). The importance of near-seated peers for elementary students' academic engagement and achievement. Journal of Applied Developmental Psychology, 57, 42-52

Hallinan, M. T. \& Smith, S. S. (1989). Classroom characteristics and student friendship cliques. Social Forces, 67(4), 898-919

Hanushek, E. A., Kain, J. F. \& Rivkin, S. G. (2009). New evidence about Brown v. Board of Education: The complex effects of school racial composition on achievement. Journal of Labor Economics, 27(3), 349-383

Kandel, D. B. (1978). Homophily, selection, and socialization in adolescent friendships. American Journal of Sociology, 84(2), 427-436

Kao, G. \& Joyner, K. (2004). Do race and ethnicity matter among friends? Activities among interracial, interethnic, and intraethnic adolescent friends. Sociological Quarterly, 45(3), 557-573

Katz, D., Allport, F. H. \& Jenness, M. B. (1931). Students' Attitudes. A Report of the Syracuse University Reaction Study. Oxford: Craftsman Press 
Keller, T. \& Takács, K. (2019). Peers that count: The influence of deskmates on test scores. Research in Social Stratification and Mobility, 62, 1-14

Kertesi, G. \& Kézdi, G. (2005). Általános iskolai szegregáció, II. rész. az általános iskolai szegregálódás folyamata Magyarországon és az iskolai teljesítménykülönbségek [Primary-school segregation II. the process of primary-school segregation in Hungary and performance differences between schools]. Közgazdasági Szemle (Economic Review-monthly of the Hungarian Academy of Sciences), 52(5), 462-479

Kisfalusi, D. (2016). The quality of inter-and intra-ethnic friendships among roma and non-Roma students in Hungary. Corvinus Journal of Sociology and Social Policy, 7(1), 3-26

Kristoffersen, J. H. G., Krægpøth, M. V., Nielsen, H. S. \& Simonsen, M. (2015). Disruptive school peers and student outcomes. Economics of Education Review, 45, 1-13

Lau, D. C. \& Murnighan, J. K. (1998). Demographic diversity and faultlines: The compositional dynamics of organizational groups. Academy of Management Review, 23(2), 325-340

Lavy, V., Silva, O. \& Weinhardt, F. (2012). The good, the bad, and the average: Evidence on ability peer effects in schools. Journal of Labor Economics, 30(2), 367-414

Lazarsfeld, P. F. \& Merton, R. K. (1954). Friendship as a social process: A substantive and methodological analysis. In M. Berger, T. Abel \& C. H. Page (Eds.), Freedom and control in modern society, (pp. 18-66). New York, NY: Van Nostrand

Leszczensky, L. \& Pink, S. (2015). Ethnic segregation of friendship networks in school: Testing a rational-choice argument of differences in ethnic homophily between classroom-and grade-level networks. Social Networks, 42, 18-26

Lomi, A., Snijders, T. A. B., Steglich, C. E. G. \& Torló, V. J. (2011). Why are some more peer than others? Evidence from a longitudinal study of social networks and individual academic performance. Social Science Research, 40(6), 1506-1520

Lu, F. \& Anderson, M. L. (2014). Peer effects in microenvironments: The benefits of homogeneous classroom groups. Journal of Labor Economics, 33(1), 91-122

Mark, N. (1998). Beyond individual differences: Social differentiation from first principles. American Sociological Review, 63(3), 309-330

Mäs, M., Flache, A., Takács, K. \& Jehn, K. A. (2013). In the short term we divide, in the long term we unite: Demographic crisscrossing and the effects of faultlines on subgroup polarization. Organization Science, 24(3), 716-736

McPherson, M., Smith-Lovin, L. \& Cook, J. M. (2001). Birds of a feather: Homophily in social networks. Annual Review of Sociology, 27, 415-444

Montello, D. R. (1988). Classroom seating location and its effect on course achievement, participation, and attitudes. Journal of Environmental Psychology, 8(2), 149-157

Moody, J. (2001). Race, school integration, and friendship segregation in America. American Journal of Sociology, 107(3), 679-716

Mouw, T. \& Entwisle, B. (2006). Residential segregation and interracial friendship in schools. American Journal of Sociology, 112(2), 394-441

Munniksma, A., Scheepers, P., Stark, T. H. \& Tolsma, J. (2017). The impact of adolescents' classroom and neighborhood ethnic diversity on same-and cross-ethnic friendships within classrooms. Journal of Research on Adolescence, 27(1), 20-33

Néray, B. (2017). Relational integration as the analysis of friendship, negative ties and ethnic identity among adolescents. Ph.D. dissertation, Corvinus University of Budapest, Faculty of Social Sciences / Doctoral School of Sociology

Newcomb, T. M. (1956). The prediction of interpersonal attraction. American Psychologist, 11(11), 575 
Newcomb, T. M. (1978). The acquaintance process: Looking mainly backward. Journal of Personality and Social Psychology, 36(10), 1075

Nowak, A., Szamrej, J. \& Latané, B. (1990). From private attitude to public opinion: A dynamic theory of social impact. Psychological Review, 97(3), 362-376

OECD (2018). Income inequality. Indicator

Pettigrew, T. F. (1997). Generalized intergroup contact effects on prejudice. Personality and Social Psychology Bulletin, 23(2), 173-185

Pettigrew, T. F. \& Tropp, L. R. (2005). Allport's intergroup contact hypothesis: Its history and influence. In J. F. Dovidio, P. Glick \& L. A. Rudman (Eds.), On the Nature of Prejudice: Fifty Years after Allport, (pp. 262-277). Malden, MA: Blackwell

Pettigrew, T. F. \& Tropp, L. R. (2006). A meta-analytic test of intergroup contact theory. Journal of Personality and Social Psychology, 90(5), 751

Radó, M. \& Kisfalusi, D. (2018). Contact theory in case of deskmate relationship. Presented at Andorka Rudolf Memorial Conference, Budapest

Rambaran, J. A., Hopmeyer, A., Schwartz, D., Steglich, C., Badaly, D. \& Veenstra, R. (2017). Academic functioning and peer influences: A short-term longitudinal study of network-behavior dynamics in middle adolescence. Child Development, 88(2), 523-543

Rathvon, N. (2008). Effective School Interventions: Strategies for Enhancing Academic Achievement and Social Competence. New York, NY: Guilford Press

Sacerdote, B. (2014). Experimental and quasi-experimental analysis of peer effects: Two steps forward? Annual Review of Economics, 6(1), 253-272

Schofield, J. W. (1991). School desegregation and intergroup relations: A review of the literature. Review of Research in Education, 17(1), 335-409

Selman, B. \& Gomes, C. P. (2006). Hill-climbing search. Encyclopedia of Cognitive Science

Shamir, J. \& Shamir, M. (1997). Pluralistic ignorance across issues and over time: Information cues and biases. Public Opinion Quarterly, 61(2), 227-260

Simmel, G. (1908). Soziologie: Untersuchungen über die Formen der Vergesellschaftung. Berlin: Dunker \& Humblot

Smith, S., Van Tubergen, F., Maas, I. \& McFarland, D. A. (2016). Ethnic composition and friendship segregation: Differential effects for adolescent natives and immigrants. American Journal of Sociology, 121(4), 1223-1272

Stark, T. H. (2015). Understanding the selection bias: Social network processes and the effect of prejudice on the avoidance of outgroup friends. Social Psychology Quarterly, 78(2), 127-150

Takács, K., Flache, A. \& Mäs, M. (2016). Discrepancy and disliking do not induce negative opinion shifts. PLoS ONE, 11(6), e0157948

Van Boven, L. (2000). Pluralistic ignorance and political correctness: The case of affirmative action. Political Psychology, 21(2), 267-276

Vinokur, A. \& Burnstein, E. (1978). Depolarization of attitudes in groups. Journal of Personality and Social Psychology, 36(8), 872-875

Wannarka, R. \& Ruhl, K. (2008). Seating arrangements that promote positive academic and behavioural outcomes: A review of empirical research. Support for Learning, 23(2), 89-93

Wilensky, U. (1999). NetLogo. http://ccl.northwestern.edu/netlogo/. Center for Connected Learning and Computer-Based Modeling, Northwestern University. Evanston, IL

Wright, S. C., Aron, A., McLaughlin-Volpe, T. \& Ropp, S. A. (1997). The extended contact effect: Knowledge of cross-group friendships and prejudice. Journal of Personality and Social psychology, 73(1), 73

Zhou, S., Page-Gould, E., Aron, A., Moyer, A. \& Hewstone, M. (2019). The extended contact hypothesis: A metaanalysis on 20 years of research. Personality and Social Psychology Review, 23(2), 132-160 